\title{
Experimental and numerical study on the flow topology of finned heat sinks with tip clearance
}

\author{
F. Sastre ${ }^{\mathrm{a}}$, A. Valeije ${ }^{\mathrm{b}}$, E. Martin ${ }^{\mathrm{b}}$, A. Velazquez ${ }^{\mathrm{a}, *}$
}

Keywords:

Heat sink

Tip clearance

Heat transfer versus pressure drop

\begin{abstract}
A B S T R A C T
An experimental and numerical study is presented that focuses on the flow topology in finned heat sinks with tip clearances. As it is well known, the use of tip clearances has, nomally, a global beneficial effect Typically, heat transfer may degrade (a negative effect) by a somewhat small percentage while pressure drop may decrease (a positive effect) by a substantial anount. In this context, the important question from an $R \& D$ standpoint is to understand the flow topology so that the actual design of the tip clearance optimizes the balance between heat transfer and pressure drop. In this study, a $3 \mathrm{D}$ numerical method is validated, first, comparing with the Particle Image Velocimetry based experimental results obtained in the actual setup in isothermal conditions. Then, the flow solver thus validated is used in a series of thermal cases in which both the tip clearance height and Reynolds number are varied so as to clarify the flow topology. In particular, it has been found that the behavior of both heat transfer and pressure drop cannot be explained in view, only, of flow development and thermal development aspects. This is so because the Nusselt versus Graetz curves that have been generated do not collapse into a single fit; instead, they collapse into several families that are governed by the tip clearance parameter. Distinct heat transfer rates have been observed for the different fin walls. The transfer rate of the side walls is nearly three times larger than that of the bottom walls, and this suggests the optimum place to locate the heat sources in a practical engineering application.
\end{abstract}

\section{Introduction}

A recurrent subject in $R \& D$ for thermal engineering application purposes is the potential advantage of implementing tip clearances in heat sink configurations with fins, pin fins, etc, to reduce pressure drop (directly related to pumping power) without imposing a large penalty on heat transfer. This is important in applications in which the pumping power for the cooling fluid cannot be increased at will but, instead, it is prescribed by some global specifications, as it happens, for example, in avionics systems. In these environments, reducing the pressure drop is critical even if a small penalty is to be paid in terms of heat transfer performance. The reason is that the global nature of the system specifications does not account for local hot spots and, thereby, the thermal engineer needs to implement local solutions that allow for an appropriate cooling performance. This happens, also, when addressing the cooling of electronics equipment of computing centers, big data centers, etc.

From an engineering standpoint, this tip clearance approach has the advantage of being passive (no moving parts or external power sources are needed) and robust. The drawback is that a positive outcome, reduced pressure drop, is counterbalanced by a negative one, smaller heat transfer rates. Then, the critical design aspect in actual engineering applications is to find out a reasonable compromise between these two contradicting effects. In this context, reaching a detailed understanding of the flow topology involved may help to approach this goal that is the objective of the present study.

To the knowledge of the authors, the first journal article published in this field was the one of Sparrow et al. [1] back in 1978. They considered a shrouded fin array with and without tip clearance. Later, Sparrow and Kaddle [2] addressed the same geometry from an experimental perspective. Other articles published up to 2010 are those of Wirtz et al. [3], Cretzer and Visser [4], Min et al. [5], Dogruoz et al. [6], Jeng [7], Rozati et al. [8], and Moores et al. [9].

More recently, Reyes et al. [10] carried out an experimental study on the effects of tip clearance on a micto channel based heat sink. The authors considered three different values for the clearance height and compared it to a reference case with no clearance present. The Reynolds number, Re, based on the hydraulic diameter of the flow passages was 


\begin{tabular}{|c|c|c|c|}
\hline \multicolumn{2}{|c|}{ Nomenclature list } & $\mathrm{Re}$ & Reynolds number \\
\hline & & $\mathrm{T}$ & Temperature $[\mathrm{K}]$ \\
\hline \multicolumn{2}{|c|}{ Latin symbols } & $\mathrm{TC}$ & Tip clearance $[\mathrm{mm}]$ \\
\hline & & $\mathrm{u}$ & Streamwise velocity component $[\mathrm{cm} / \mathrm{s}]$ \\
\hline$A_{w}$ & Wall area $\left[\mathrm{m}^{2}\right]$ & $\mathrm{v}$ & Velocity vector $[\mathrm{cm} / \mathrm{s}]$ \\
\hline C & Configuration & W & Wall \\
\hline $\mathrm{Cp}_{\mathrm{p}}$ & Specific heat $[\mathrm{J} /(\mathrm{kg} \mathrm{K})]$ & $\mathrm{x}$ & Spatial coordinate $[\mathrm{m}]$ \\
\hline $\mathrm{CS}$ & Cross section $\left[\mathrm{cm}^{2}\right]$ & $\mathrm{y}$ & Spatial coordinate $[\mathrm{m}]$ \\
\hline $\mathrm{D}_{\mathrm{H}}$ & Hydraulic diameter $[\mathrm{cm}]$ & $\mathrm{z}$ & Spatial coordinate $[\mathrm{m}]$ \\
\hline $\mathrm{H}$ & Channel height $[\mathrm{mm}]$ & & \\
\hline $\mathrm{h}$ & Heat transfer coefficient $\left[\mathrm{W} /\left(\mathrm{K} \mathrm{m}^{2}\right)\right]$ & \multicolumn{2}{|c|}{ Greek symbols } \\
\hline k & Thermal conductivity $[\mathrm{W} /(\mathrm{K} \mathrm{m})]$ & & \\
\hline L & Channel length $[\mathrm{m}]$ & $\varepsilon$ & Deviation \\
\hline $\mathrm{Nc}$ & Number of cells & $\rho$ & Flow density $\left[\mathrm{kg} / \mathrm{m}^{3}\right]$ \\
\hline $\mathrm{Nu}$ & Nusselt number & $\mu$ & Flow viscosity $[\mathrm{kg} /(\mathrm{m} \mathrm{s})]$ \\
\hline $\mathrm{p}$ & Pressure $[\mathrm{Pa}]$ & \multirow{2}{*}{\multicolumn{2}{|c|}{ Subscripts }} \\
\hline $\operatorname{Pr}$ & Prandtl number & & \\
\hline Q & Volume flow rate $[\mathrm{l} / \mathrm{h}]$ & & \\
\hline $\mathrm{Q}_{\mathrm{W}}$ & Heat transfer rate $[\mathrm{W}]$ & $\infty$ & Conditions at the inlet section \\
\hline
\end{tabular}

varied between 400 and 2600 . The working fluid was water and the heat sink wall temperature was kept constant and equal to $70^{\circ} \mathrm{C}$. At the lowest $\mathrm{Re}$, the authors found that pressure drop and heat transfer were very sensitive to the tip clearance. The optimum configuration was the one in which the tip clearance $(500 \mu \mathrm{m})$ was equal to the fin height. In this case, the ensuing Nusselt number, $\mathrm{Nu}$, was 0.83 times the reference $\mathrm{Nu}$, while the pressure drop, $\Delta \mathrm{P}$, was 0.20 times the reference $\Delta \mathrm{P}$. However, for the highest Re, it was observed that both heat transfer and pressure drop showed a weak dependence on the tip clearance. Specifically, heat transfer degradation and pressure drop improvement rates at the higher Re were similar regardless of the tip clearance height.

Tullius et al. [11] addressed the problem of optimization of micro pin fins in minichannels. Their study was of a numerical nature and several clearance ratios were considered. They reported the contradicting effect of pressure losses versus heat transfer mentioned earlier. In particular, they showed that pressure drop had a greater sensitivity with regard to the problem governing parameters than heat transfer. Interestingly enough, they were able to generate a correlation for $\mathrm{Nu}$ that accounted for the tip clearance height as well. An experimental study on the influence of the tip clearance in a group of micro-cylinders placed on a heat sink has been described by Liu et al. [12]. The authors concentrated on the low Re regime and for Re 400 and the optimum clearance they reported a $15 \%$ deterioration of heat transfer and a $50 \%$ reduction of pressure losses as compared to their reference case. Liang et al. [13] have extended these studies to the case in which the working fluid is non-Newtonian (power-law polymeric in their case) and found similar qualitative trends. Mei et al. [14] studied the effect of tip clearance in micro-pin type geometries and reported heat transfer degradation rates of the order of $50 \%$ with reduction of pressure losses by a factor of about 4 .

The effect of tip and lateral clearance on a new heat sink concept has been addressed by Ho et al. [15]. In this article, besides an experimental study, the authors proposed a semi-analytical model that could be used for designing purposes. An experimental study that accounts for, among other aspects, the influence that tip clearances have on the thermal performance of pin-fin arrays has been published by $\mathrm{Li}$ [16]. In this study, the authors were able to find linear correlations between thermal performance, Re and tip to outer surface distance. Jadhav and Balaji [17] have presented yet another experimental study and it is worth to note that they report in their conclusions that the effect of tip clearance on thermal performance is more pronounced at lower flow velocities. Finally, it is worth mentioning the computational study of Giri and Das [18]. These authors considered a shrouded rectangular fin array and they varied clearance spacing, fin spacing and
Re. In their conclusions they suggested the presence of potentially optimum values for the clearance.

Summarizing, there is a common qualitative tendency in all the above mentioned references regardless of the type of geometry under consideration (square section pin fin, circular section pin fin, conventional straight fin, etc.). Namely: the main effect of tip clearance is to degrade heat transfer somewhat while alleviating pressure losses significantly. However, actual quantification of these effects appears to be very much problem dependent. So, in this context, the objective of the present study is to focus on a single, and very general, geometry, heat sink with straight fins and tip clearance, and clarify its actual flow topology. To do it, the study being presented is of a dual nature: experimental and numerical. Obviously, it would have been much better to perform a fully experimental work. However, the geometry being considered was three dimensional and complex, and the most reliable information provided by the Particle Image Velocimetry technique, PIV, was limited to some specific planes that were not fully representative of the actual 3D topology. Then, the strategy was to perform a series of isothermal experiments on the test model and use the results to validate the 3D flow solver via comparison with local PIV data. Then, thus validated, the flow solver was applied to the thermal cases. Regarding organization of the article: section 2 describes the experimental setup, section 3 presents the flow solver, isothermal experimental results and comparison with their numerical counterparts are given in section 4, computational thermal cases are presented and discussed in section 5, and, finally, conclusions are stated in section 6.

\section{Description of the experimental setup}

The experimental model was manufactured out of methacrylate. It basically consisted of four square section channels connecting two stagnation chambers. The cross section dimensions of the channels were $10 \mathrm{~mm} \times 10 \mathrm{~mm}$ and their length was $250 \mathrm{~mm}$. The upstream stagnation chamber had the following dimensions: length $200 \mathrm{~mm}$, span $90 \mathrm{~mm}$ and depth $20 \mathrm{~mm}$. The dimensions of the downstream stagnation chamber were: length $50 \mathrm{~mm}$, span $90 \mathrm{~mm}$ and depth $20 \mathrm{~mm}$. It could be observed that the depth of the stagnation chambers $(20 \mathrm{~mm})$ was twice the channel cross section height $(10 \mathrm{~mm})$. This means that the flow had to go through a forward step like structure before entering the channels. A sketch of the basic platform is shown in Fig. 1.

Three different models were manufactured: the so-called configurations $\mathrm{C} 0, \mathrm{C} 1$ and $\mathrm{C} 2$. Configuration $\mathrm{C} 0$ was the reference configuration because the top cover was pressed directly over the fins (no tip clearance present). In configurations $\mathrm{C} 1$ and $\mathrm{C} 2$ the covers were 


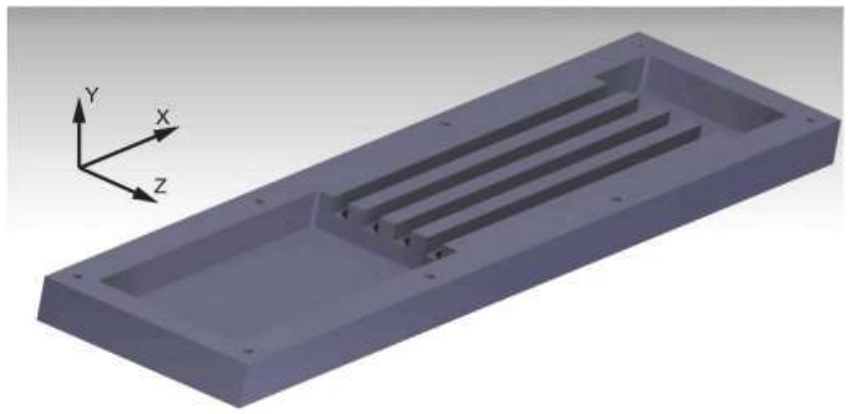

$S_{0}$ to $S_{5}$ were located on the channels between fins and on top of the fins.

Water was propelled using an ITT Totton centrifugal pump with a magnetic drive DC15/5". The flowmeter was a Siemens Sitrans FM MAG1100 equipped with a Sitrans FM MAG5000 transmitter. Its measurement uncertainty was $\pm 5 \%$. Pressure differences were measured using a Gems Sensor. This sensor measured in the range of $-1000 \mathrm{~Pa}$ to $+1000 \mathrm{~Pa}$ with an uncertainty of $1 \%$. These were the specifications provided by the manufacturer. The authors measured, also, pressure differences up to $1500 \mathrm{~Pa}$ whose uncertainty of $1 \%$ cannot be guaranteed by the sensor manufacturer. It is clear that measurement uncertainties should not be validated using numerical results. However, in this case, the numerical computations showed good agreement with the measurements in that range which suggests that, as an indication, not as a validation, the sensor could be reasonably used up to $1500 \mathrm{~Pa}$. The actual pressure drop was measured in between the inlet and outlet lines. Water temperature was measured during the experiments and checked to be $20{ }^{\circ} \mathrm{C}$ with maximum deviations of the order of $\pm 0.5^{\circ} \mathrm{C}$.

Four volume flow rates (Q1 to Q4) were tested for each of the three configurations $\mathrm{C} 0, \mathrm{C} 1$ and $\mathrm{C} 2$. The actual volume flow rates figures (in liters per hour) are given in Table 1. Re for these volume flow rates and configuration $\mathrm{CO}$ (Re was based on the hydraulic diameter and average velocity at the channels cross-section) are also shown in Table 1 . These Re are similar to those used in Reyes et al. [10]. Q1 to Q3 are in the laminar regime while $\mathrm{Q} 4$ could be considered to be close the beginning of the transitional regime.

A Dantec Dynamics PIV system was used for characterization pur-

Fig. 1. Sketch of the experimental platform for configuration C0. Top) view of the upstream and downstream stagnation chambers and channels. Bottom) view of the system closed with the two inlet and two outlet lines. Only the fluid domain is shown.

manufactured so as to allow for tip clearances, TC, of $5 \mathrm{~mm}$ and $10 \mathrm{~mm}$ respectively ( $50 \%$ and $100 \%$ of the fin height). These percentages were similar to those used in Ref. [10]. To homogenize the flow in the upstream stagnation chamber, a plastic honeycomb (manufactured with a 3D printer) and a series of five grids framed into a single piece were inserted right downstream of the inlet flow lines. Fig. 2 shows a photograph of the devices inserted into the model.

The upstream stagnation chamber was fed with two water lines that discharged into the chamber perpendicular to the top cover. The inner diameter of each line was $8 \mathrm{~mm}$. A sketch (top and side views, a schematics and a photograph) of the basic setup is presented in Fig. 3. The top subplot of Fig. 3 provides information on the location of the planes (Pl1, Pl2, Pl3, Pl25, and Pl 35) where PIV measurements were actually taken. $\mathrm{Pl} 2$ and $\mathrm{Pl} 3$ covered part of the stagnation chamber and the center plane of the channels. Pl1, Pl25 and Pl35 covered part of the stagnation chamber and the tip clearance areas. The top subplot of Fig. 3 also provides information on the sections $\left(S_{-3}\right.$ to $\left.S_{5}\right)$ where actual comparison between PIV measurements and CFD results was carried out. Sections $\mathrm{S}_{-3}$ to $\mathrm{S}_{-1}$ were located in the stagnation chamber. Sections poses. The pulsed laser system was a Nd:YAG $800 \mathrm{~ms}$. The time lapse between pulses $5 \mathrm{~ms}$. The Dantec Dynamics Flow Sense 2ME camera had a resolution of $1600 \times 1200$ pixels. Hollow glass spheres HGS-10 whose diameter were $10 \mu \mathrm{m}$ were used for flow seeding purposes. Synchronization between image capturing and flow illumination was achieved using the Dantec Dynamics Studio software. The size of the interrogation areas was $100 \mathrm{~mm} \times 75 \mathrm{~mm}$. These areas were partitioned into smaller areas by the PIV software to converge the re-computation of the flow field. The time span between laser pulses (required to collect a flow snapshot) was $5 \mathrm{~ms}$. In the worst case scenario of the maximum flow velocity (configuration $\mathrm{CO}$ at the highest flow rate), a particle would travel of the order of $0.6 \mathrm{~mm}$ between pulses that is a distance much smaller than the problem characteristic length of $10 \mathrm{~mm}$ (the fin height). That is: the problem characteristic length in the most critical case was of the order of 17 times the PIV spatial resolution. In the most favorable case, the ratio of the problem characteristic length to the PIV spatial resolution was 188 .

Regarding the repeatability of the measurements, 300 frames were collected for each capture and 15 captures were taken for each of the 12 cases (four volume flow rates times three configurations). However, for a few cases, believed to be critical, 600 frames for each capture were taken instead. It was assumed that the worst scenario was the one with highest flow rate (Q4) and largest tip clearance (C2). The reason is that
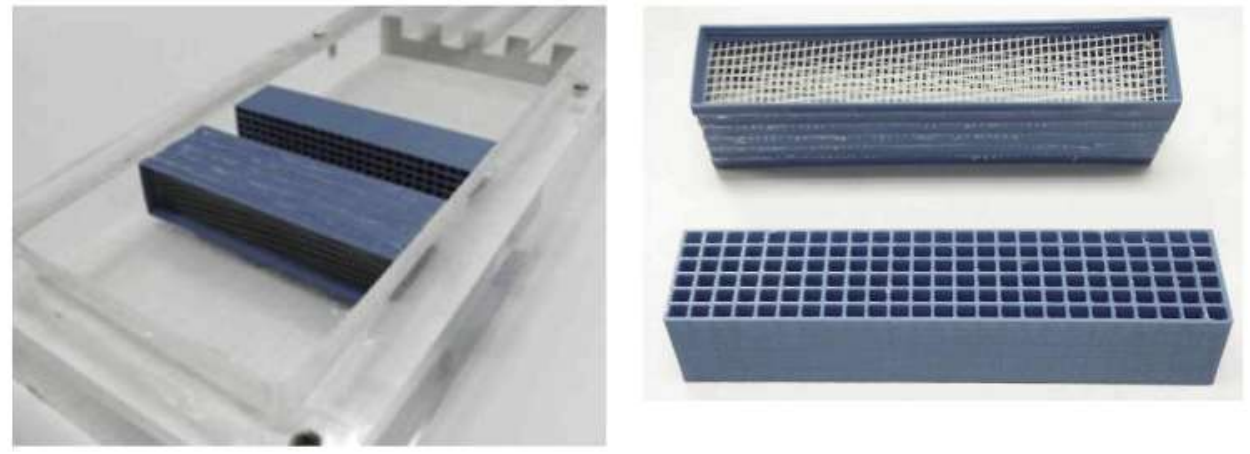

Fig. 2. Photograph of the device for configuration $\mathrm{CO}$ (left), and honeycomb and grid inserted into the upstream stagnation chamber (right). 

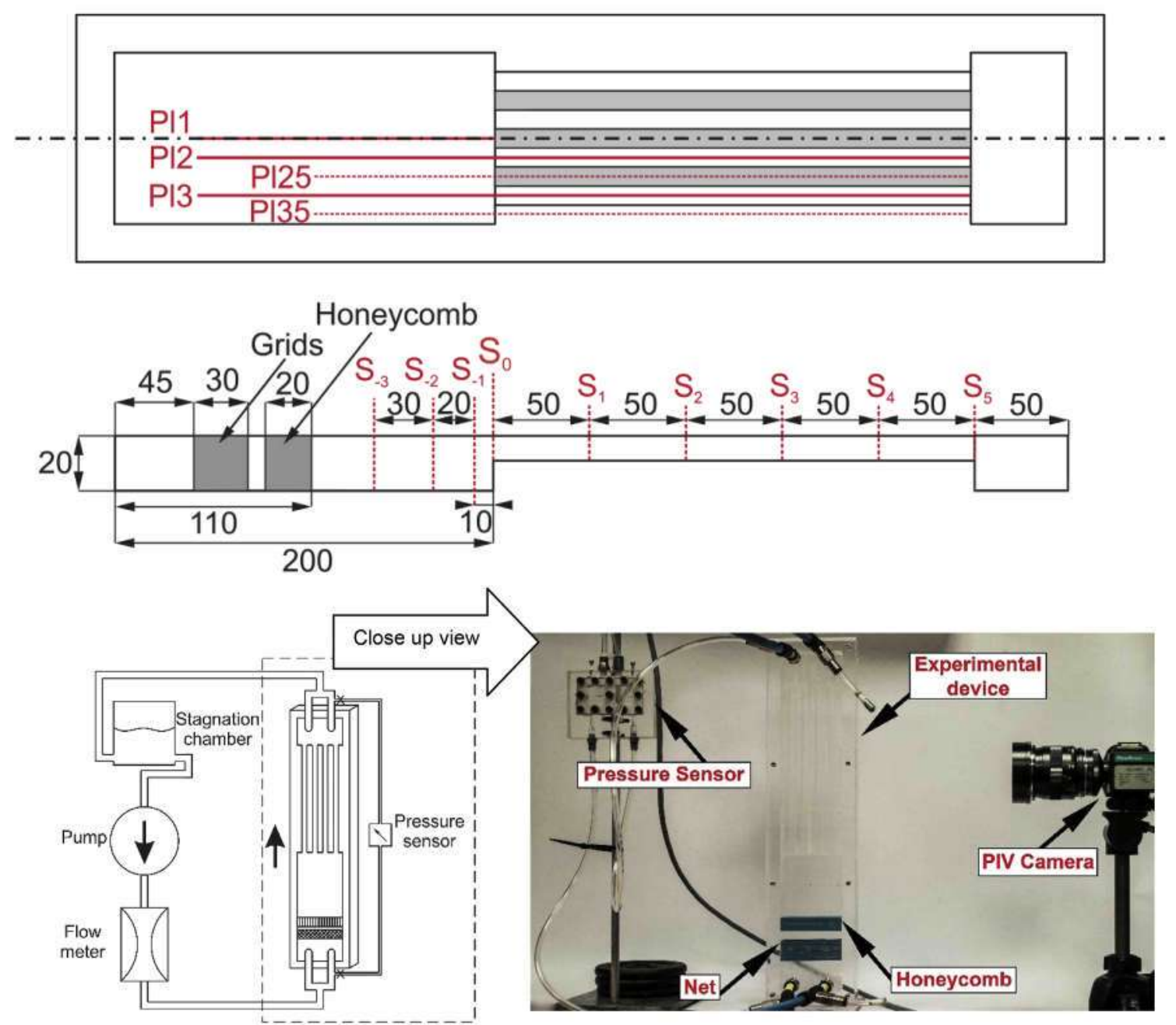

Fig. 3. Top) detail of the experimental setup for configuration $\mathrm{C} 2$ and planes ( $\mathrm{Pl} 1, \mathrm{Pl} 2, \mathrm{Pl}$, Pl25, and Pl 35) and sections ( $\mathrm{S}-3$ to $\mathrm{S} 5$ ) used for comparison between experimental and numerical results. Measurements are given in $\mathrm{mm}$. Bottom left) schematics of the installation. Bottom right) close up view of the installation. The two crosses in bottom left figure mark the position of the pressure sensors.

Table 1

Volume flow rates (Q1 to Q4) in liters per hour used in the experiment, and associated Re for configuration Co.

\begin{tabular}{lll}
\hline Case key & Flow rate $(1 / \mathrm{h})$ & Re $(\mathrm{C} 0)$ \\
\hline Q1 & 53.5 & 416 \\
Q2 & 83.6 & 650 \\
Q3 & 110.3 & 858 \\
Q4 & 167.2 & 1300 \\
\hline
\end{tabular}

the combination of highest flow rate and largest tip clearance lead to the stronger 3D effects. A very small Re (think, for instance, of the Stokes limit) or the situation with no tip clearance (configuration $\mathrm{C} 0$ ) would present nearly a 2D flow. In this case, the most critical measurement sections were $\mathrm{S}_{-1}, \mathrm{~S}_{0}$ and $\mathrm{S}_{1}$ (see Fig. 3). Fig. 4 shows the uncertainty bands for the horizontal velocity in this case (Q4/C2 in sections $\mathrm{S}_{-1}, \mathrm{~S}_{0}$ and $\mathrm{S}_{1}$ ) and the actual histogram of the measurements at a height of $20 \mathrm{~mm}$ above the lowest surface of the stagnation chamber. Afterwards it was checked that these bands represented the worst case as compared to the others.

\section{Description of the flow Solver and computational domain}

The standard OpenFOAM ${ }^{\circ} \mathrm{C}++$ library simpleFoam [19] has been used to simulate the steady laminar isothermal problem in the device described in the previous section. The set of continuity and momentum dimensionless equations solved was:

$\widetilde{\nabla} \cdot \widetilde{v}=0$

$\tilde{v} \cdot \widetilde{\nabla} \tilde{v}=-\widetilde{\nabla} \widetilde{P}+\widetilde{\nabla} \cdot\left(\frac{1}{R e} \tilde{\mu} \widetilde{\nabla} \tilde{v}\right)$

where $\tilde{v}=\widetilde{u} \vec{i}+\vec{v} \vec{j}+\widetilde{w} \vec{k}$, stands for the dimensionless velocity in the $\mathrm{x}, \mathrm{y}$, and $\mathrm{z}$ coordinates (see Fig. 1) while $\widetilde{P}$ represents the dimensionless pressure. Additionally, for the non-isothermal cases, the following heat transfer equation was implemented for the temperature $\widetilde{T}$ :

$\tilde{v} \cdot \widetilde{\nabla} \widetilde{T}=\widetilde{\nabla} \cdot\left(\frac{1}{\operatorname{RePr}} \tilde{k} \widetilde{\nabla} \widetilde{T}\right)$

The independent and dependent variables were made dimensionless as follows:

$\tilde{x}=\frac{x}{D_{H}}, \tilde{y}=\frac{y}{D_{H}}, \tilde{z}=\frac{z}{D_{H}}$

$\tilde{u}=\frac{u}{U_{\infty}}, \tilde{v}=\frac{v}{U_{\infty}}, \widetilde{w}=\frac{w}{U_{\infty}}, \widetilde{P}=\frac{P}{P_{\infty} U_{\infty}^{2}}, \tilde{T}=\frac{T}{T_{\infty}}$

where $D_{H}$ is the reference length (the hydraulic diameter of the device cross-section in the region where the channels are located), $U_{\infty}$ is the mean fluid velocity at that cross section, and $\rho_{\infty}$ and $T_{\infty}$ are the water 

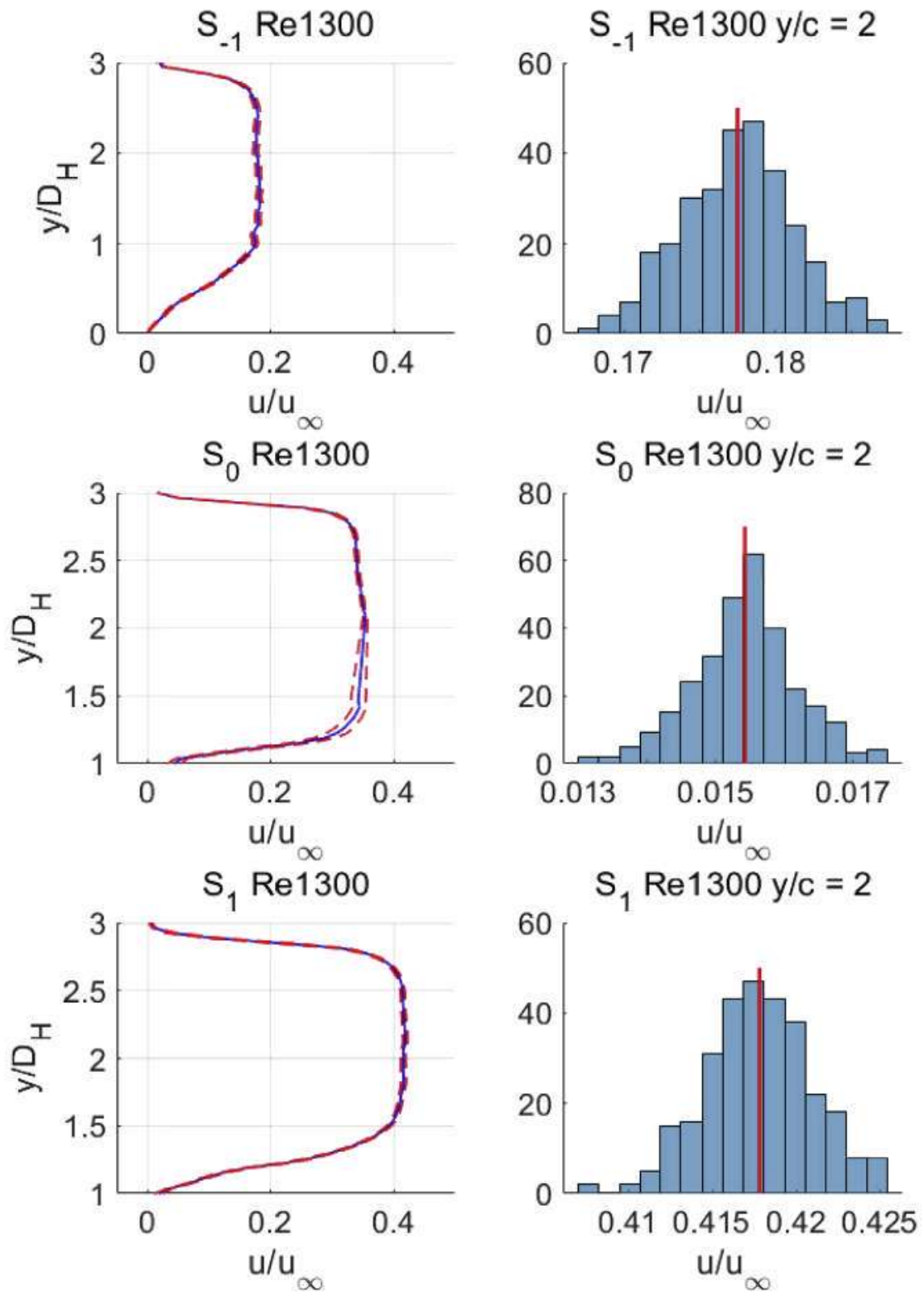

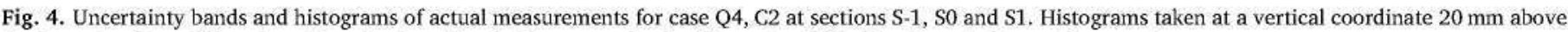
the lowest surface of the stagnation chamber. $U_{\infty}$ is the mean velocity (flow rate divided by the actual cross flow area).
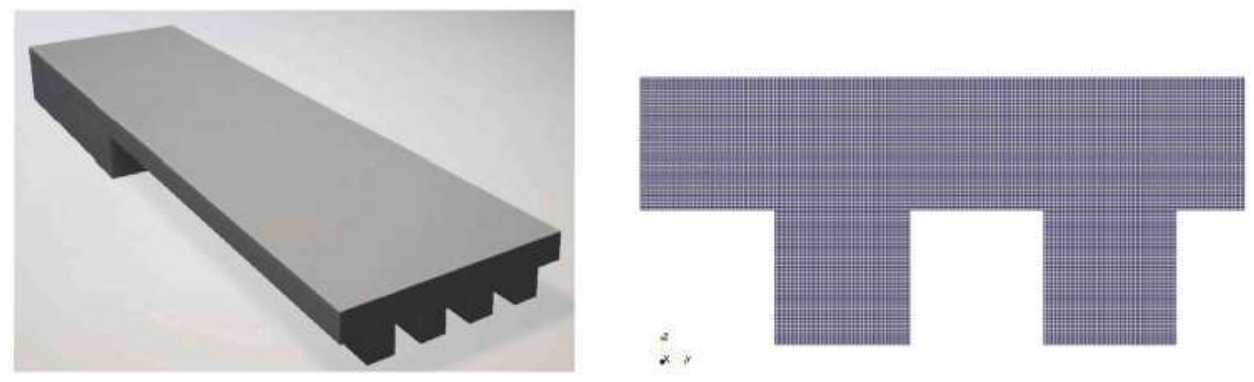

Fig. 5. Left) Partial view of the computational domain for configuration C2. Right) Half the mesh at the cross section where the left view of the domain is stopped.

density and temperature at the inlet The Reynolds and Prandtl numbers were defined as:

$\operatorname{Re}=\frac{\rho_{\infty} U_{\infty} D_{H}}{\mu_{\infty}}, \operatorname{Pr}=\frac{\mu_{\infty} C P_{\infty}}{k_{\infty}}$, specific heat evaluated at the inlet temperature. Finally, $\tilde{\mu}$ and $\tilde{k}$ stand for the fluid dimensionless viscosity and conductivity that are temperature dependent and characteristic of the working fluid. Expressions for water in eqs. (7) and (8) have been obtained from Martin and Velazquez [20]:

where $\mu_{\infty}, k_{\infty}$ and $C P_{\infty}$ stand for the fluid viscosity, conductivity and 


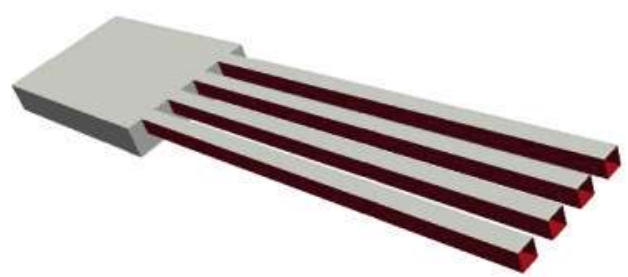

Table 2

Mesh sensitivity analysis for the thermal case C2-Q4. Three meshes (\#1,\#2, and\#3) were considered. The finer mesh\#3 was assumed to be the reference mesh. Table shows mesh data (Nc: number of cells and size of elements), relative discrepancy of the streamwise velocity profile at $S_{s_{1}}(\varepsilon 1)$, and relative discrepancy $(\varepsilon 2)$ of the total heat transfer.

\begin{tabular}{lllllll}
\hline Mesh & Nc & $\Delta \tilde{x}$ & $\Delta \tilde{y}$ & $\Delta \tilde{z}$ & $\varepsilon 1$ & $\varepsilon 2$ \\
\hline$\# 1$ & $3.4 \times 10^{6}$ & 0.10 & 0.04 & 0.04 & $6.2 \%$ & $7.7 \%$ \\
$\# 2$ & $7.7 \times 10^{6}$ & 0.075 & 0.03 & 0.03 & $2.3 \%$ & $1.4 \%$ \\
$\# 3$ & $26.4 \times 10^{6}$ & 0.05 & 0.02 & 0.20 & Ref. & Ref. \\
\hline
\end{tabular}
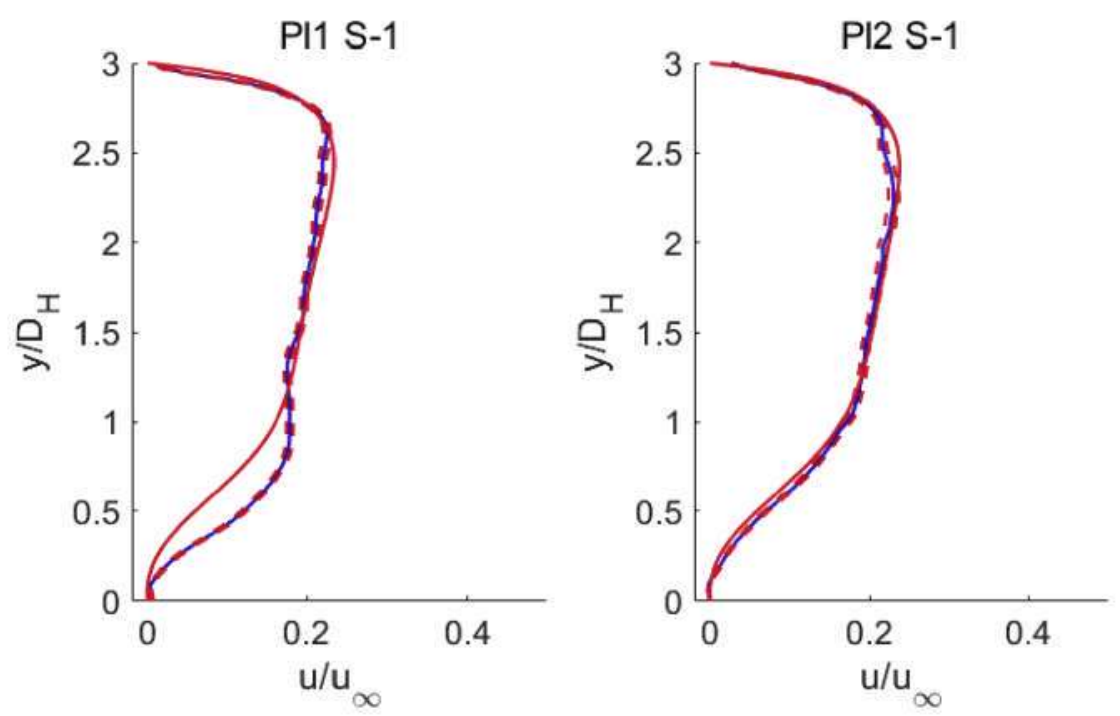

Fig. 6. Thermal boundary conditions for computational domains CO (left) and C2 (right). Constant temperature walls depicted in red color, adiabatic walls in grey color. (For interpretation of the references to color in this figure legend, the reader is referred to the Web version of this article.)

$$
\begin{aligned}
& \tilde{\mu}(\tilde{T})=\frac{\mu(T)}{\mu_{\infty}}=1-5.646(\widetilde{T}-1)+12.259(\widetilde{T}-1)^{2}, \\
& \tilde{k}(\widetilde{T})=\frac{k(T)}{k_{\infty}}=1+0.786(\widetilde{T}-1)+1.176(\widetilde{T}-1)^{2}
\end{aligned}
$$

The adaptation of the solver simpleFoam, which is based on a finite volume formulation (Ferziger and Milovan [21], OpenFOAM User Guide [22]) for a laminar steady flow was carried out, adding, in a very simple way, the heat flow equation (3) and creating additional functions for the transport dimensionless variables $\tilde{\mu}(\widetilde{T})$ and $\tilde{k}(\widetilde{T})$ that are evaluated for each iteration. The solver simpleFoam uses the pressurevelocity coupling SIMPLE (Semi-Implicit Pressure Linked Equations)

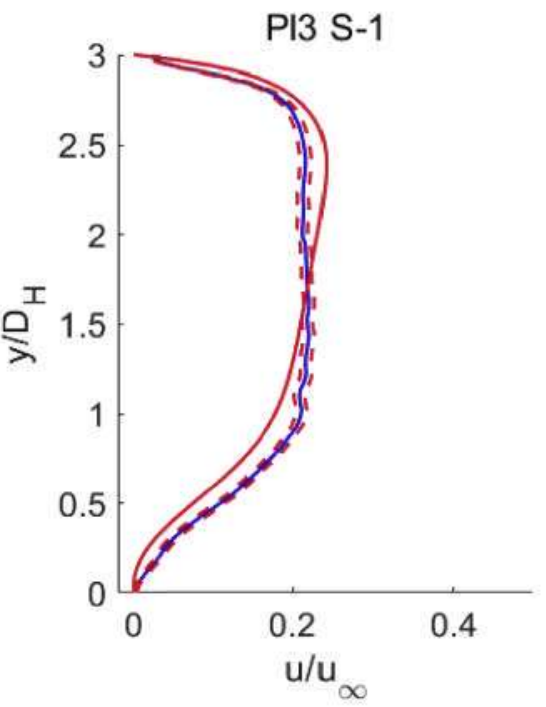

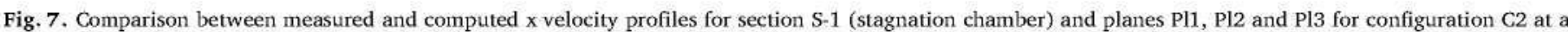

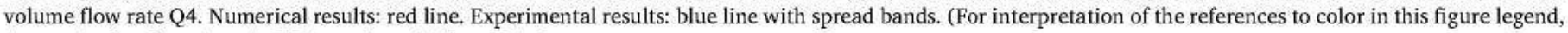
the reader is referred to the Web version of this article.) 

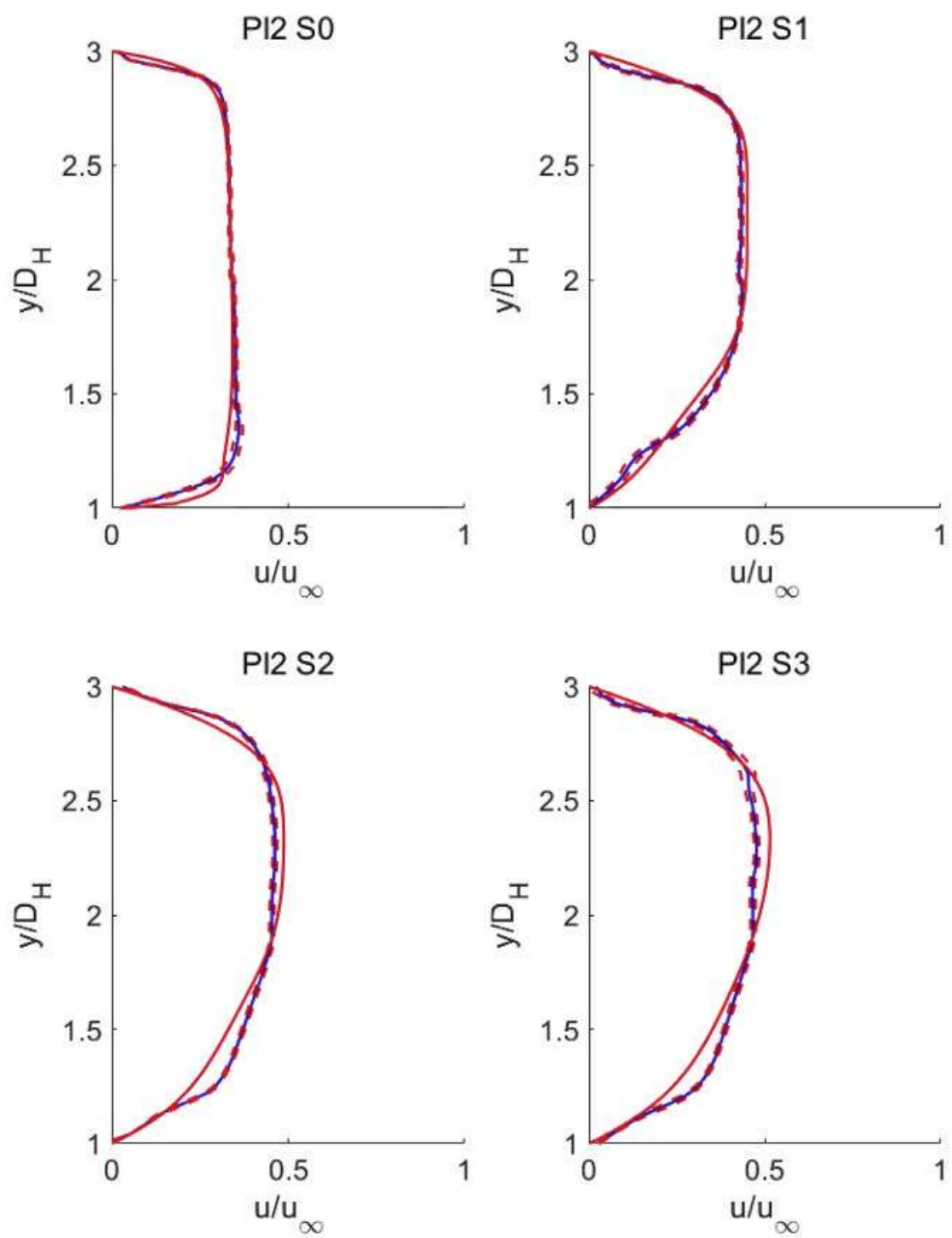

Fig. 8. Counterpart of Fig. 7 but, now, for the flow along a channel center line. Numerical results: red line. Experimental results: blue line with spread bands. (For interpretation of the references to color in this figure legend, the reader is referred to the Web version of this article.)

algorithm proposed by Caretto et al. [23] to generate a pressure field that fulfills the continuity equation (1). This algorithm is organized into three steps: a) a guessed velocity field is obtained from the last iteration pressure field, b) a pressure correction equation is solved, and c) the pressure thus obtained is used to correct the velocity field in a way that the mass conservation equation is fulfilled. The under-relaxation factor used in this work for the simpleFoam solver (Jasak [24]) was 0.3. Other solution variables were under-relaxed by a factor of 0.7 to accelerate convergence.

The discretization schemes chosen for each term of equations (2) and (3) are the following: second order Gaussian spatial integration schemes for the diffusive terms and gradient terms, and linear upwind differencing interpolation schemes for the convective terms were chosen. The segregated linear systems obtained upon discretization of the problem were solved with different iterative methods (Saad [25]): equations for the velocity were solved using a Gauss-Seidel smoothed solver, while a GAMG (Geometric Algebraic Multi Grid) algorithm was applied for the pressure and temperature equations. This algorithm solves the equation, first, on a coarse grid and then, step by step, increases the grid resolution. This mapping of the coarse solution onto the finer grid leads to good convergence rates. Gauss-Seidel schemes were chosen as smoothers (Moukalled et al. [26]). Absolute tolerances of
$10^{-6}$ were selected for the problem.

To validate the implementations introduced in the standard simpleFoam solver to include the thermal equation (3) and its related boundary conditions, numerical tests on a squared channel of $10 \mathrm{~mm}$ height and $500 \mathrm{~mm}$ long were carried out imposing a dynamically developed flow of inlet Reynolds number 100 (based on the channel hydraulic diameter $\mathrm{D}_{\mathrm{H}}$ ) with a uniform inlet temperature of $35^{\circ} \mathrm{C}$. The channel walls were at a constant uniform temperature of $70^{\circ} \mathrm{C}$. The fluid was water with constant transport properties evaluated at the inlet temperature. For this simple geometry, the global Nusselt number of 2.98 for the thermally fully developed flow is well known (Shah and London [27]). The numerical results led to a constant Nusselt value of 2.79 reached at a dimensionless distance from the inlet $\left(\mathrm{x} / \mathrm{D}_{\mathrm{H}} \mathrm{Re}_{\mathrm{DH}} \mathrm{Pr}\right)$ of 0.07 , that are in very good agreement with the results of Lyczkowsky et al. [28].

The description of the four computational domains tested numerically (see Fig. 5), both for the isothermal and thermal problem, is as follows. The inlet of the computational domains coincides with the entrance to the grids while the outlet matches $\mathrm{S}_{5}$ (see Fig. 3 ) for all configurations $\mathrm{C} 0, \mathrm{C} 1$ and $\mathrm{C} 2$. The other boundaries of the computational domain match the walls of the device for each configuration. Additionally, a fourth computational domain, corresponding to a device 

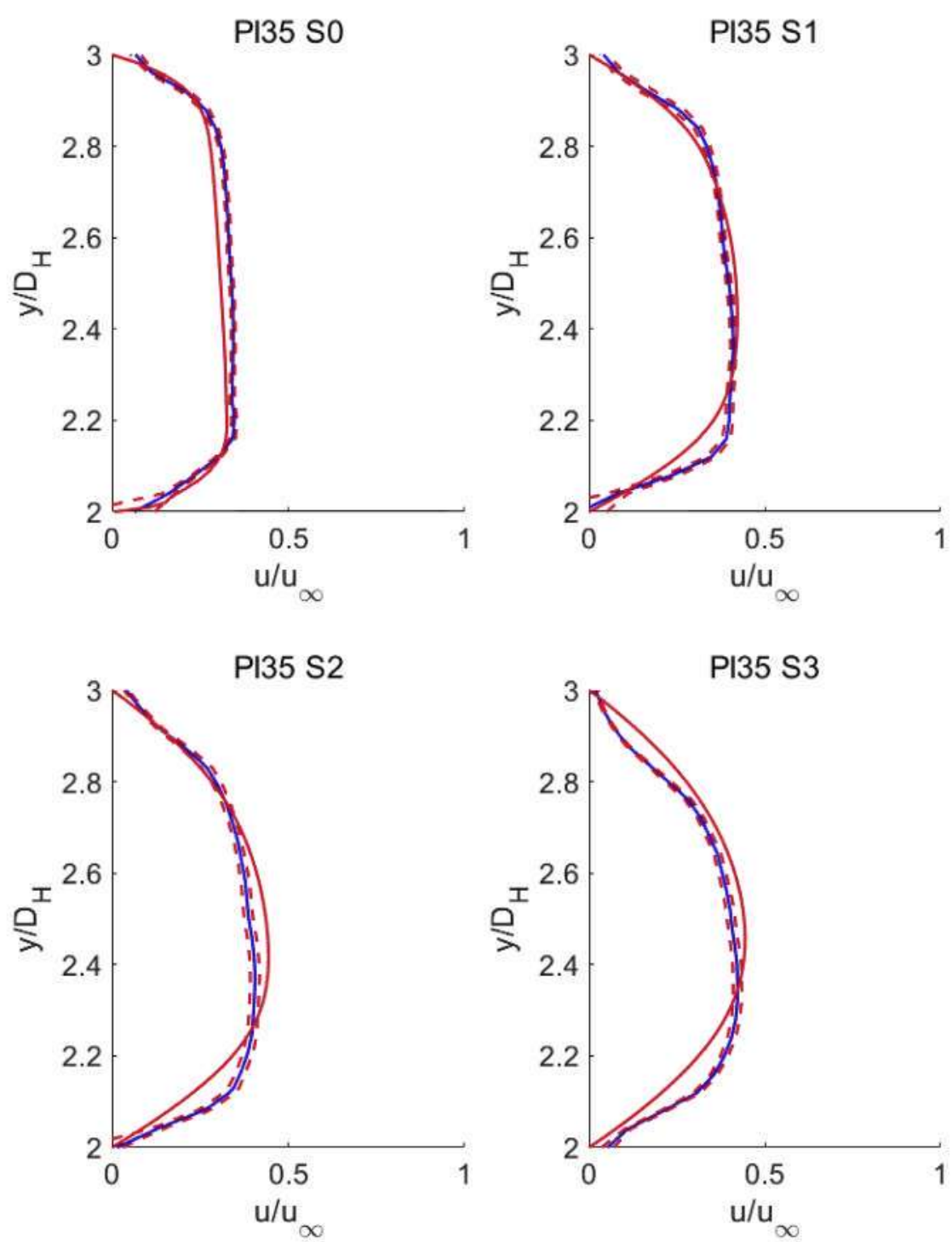

Fig. 9. Counterpart of Figure but, now, for the flow along the top of a fin. Numerical results: red line. Experimental results: blue line with spread bands. (For interpretation of the references to color in this figure legend, the reader is referred to the Web version of this article.)

Table 3

Comparison between experimental and numerical pressure drops (inlet to outlet water lines) for the isothermal configuration C0. Discrepancies $(\varepsilon 3)$ are expressed in percentages.

\begin{tabular}{lllll}
\hline Flow rate & Re & $\Delta P_{\text {exp }}(\mathrm{Pa})$ & $\Delta P_{\text {num }}(\mathrm{Pa})$ & $\varepsilon$ \\
\hline Q1 & 416 & 57 & 55 & $3.6 \%$ \\
Q2 & 650 & 130 & 123 & $5.4 \%$ \\
Q3 & 858 & 195 & 180 & $7.7 \%$ \\
\hline
\end{tabular}

with a tip clearance of $20 \mathrm{~mm}$ ( $200 \%$ of the fin height) also analyzed in Ref. [10], named con configuration C3, was simulated. Neither the grid nor the honeycomb were modeled in the computational domains that made up the matrix of cases to be analyzed. In a single case (described at the end of this section) the honeycomb was also modeled for comparison purposes. However, the computational cost associated to this particular case was so high that it was decided not to use it for the computation of the matrix of cases. Uniform boundaries conditions for the normal dimensionless velocity (corresponding to each of the four volumetric flows Q1, Q2, Q3 and Q4) and temperature for the thermal tests (of $35^{\circ} \mathrm{C}$ ) were imposed at the inlet, while standard boundary conditions of $\widetilde{P}=0$ and zero normal gradients for the other variables were used at the outlet. At the walls, a no slip condition was imposed while for the thermal cases all walls were insulated except for the section of platform wall along the channel region (from $S_{0}$ to $S_{5}$ ), that was considered to be at a constant temperature of $70^{\circ} \mathrm{C}(\widetilde{T}=1.114)$. Fluid properties for the isothermal test were calculated for a temperature of $20^{\circ} \mathrm{C}$. For clarification purposes, Fig. 6 shows in red color the constant temperature walls, and in grey color the adiabatic walls for configuration $\mathrm{C} 0$ and $\mathrm{C} 2$. Uniform structured meshes with cell sizes of $\Delta \tilde{x}=0.05, \Delta \tilde{y}=\Delta \tilde{z}=0.02$ for each domain were generated with the snappyHexMesh utility, leading to meshes of 17.5, 23.5, 26.4 and 40.5 millions of cells for configurations $\mathrm{C} 0, \mathrm{C} 1, \mathrm{C} 2$ and $\mathrm{C} 3$, respectively. Fig. 5, shows a partial view of the C2 computational domain and half the mesh at the cross section, where the former view is stopped.

A sensitivity analysis was performed in two coarser grids for the thermal problem of configuration C2 domain with volumetric flow Q4 (C2-Q4). Comparison of global errors of the streamwise velocity profile at $\mathrm{S}_{-1}$ and of the total heat transfer results is shown in Table 2 taking as reference the results obtained with the final mesh (Mesh 3 ).

Computational times in excess of $60 \mathrm{~h}$ were necessary to solve the thermal case $\mathrm{C} 2-\mathrm{Q} 4$ with the reference mesh on an Intel ${ }^{\circ}$ Xeon E5$2620 \mathrm{v} 3$ processor of $2.4 \mathrm{GHz}$ in a $128 \mathrm{~Gb}$ RAM workstation.

In addition to the computational domains described before, a more 


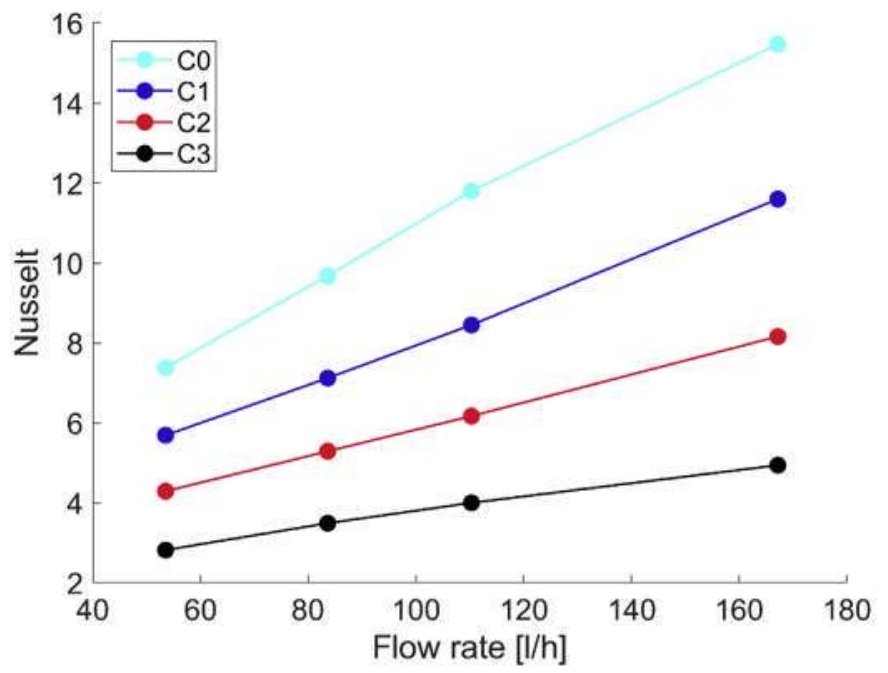

Fig. 10. Nu versus flow rate for configurations $\mathrm{CO}$ to $\mathrm{C} 3$.

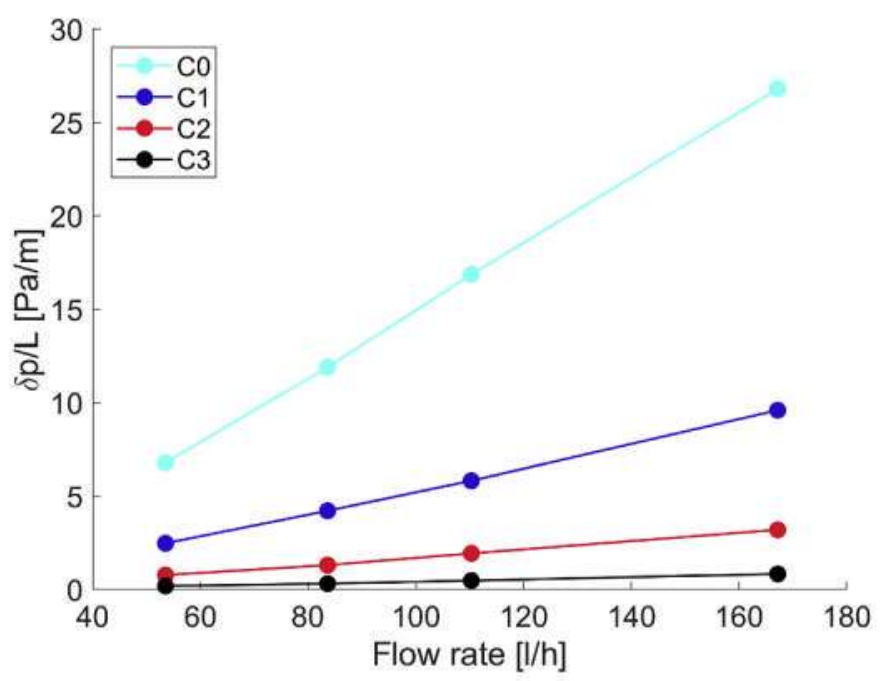

Fig. 11. Pressure drop versus flow rate for configurations $\mathrm{C} 0$ to $\mathrm{C} 3$.

Table 4

Cross section area, CS, mean velocity, $\mathrm{U}_{\infty}$, Re, hydraulic diameter and computed $\left(\Delta \mathrm{P}_{\mathrm{CFD}}\right)$ and estimated $\left(\Delta \mathrm{P}_{\text {est }}\right)$ pressure drops for the 16 cases ( $\mathrm{CO}$ to $\mathrm{C} 3$, Q1 to Q4) that have been considered.

\begin{tabular}{llllllll}
\hline $\mathrm{C}$ & $\mathrm{Q}$ & $\mathrm{CS}\left(\mathrm{cm}^{2}\right)$ & $\mathrm{U}_{\omega}(\mathrm{cm} / \mathrm{s})$ & $\mathrm{Re}$ & $\mathrm{D}_{\mathrm{H}}(\mathrm{cm})$ & $\Delta \mathrm{P}_{\mathrm{CFD}}(\mathrm{Pa})$ & $\Delta \mathrm{P}_{\text {est }}(\mathrm{Pa})$ \\
\hline $\mathrm{C} 0$ & $\mathrm{Q} 1$ & 4.0 & 3.72 & 560 & 1.00 & 1.70 & 0.80 \\
$\mathrm{C} 0$ & $\mathrm{Q} 2$ & 4.0 & 5.81 & 874 & 1.00 & 2.98 & 1.36 \\
$\mathrm{C} 0$ & $\mathrm{Q} 3$ & 4.0 & 7.66 & 1154 & 1.00 & 4.23 & 1.91 \\
$\mathrm{C} 0$ & $\mathrm{Q} 4$ & 4.0 & 11.61 & 1748 & 1.00 & 6.70 & 3.30 \\
$\mathrm{C} 1$ & $\mathrm{Q} 1$ & 8.5 & 1.75 & 332 & 1.26 & 0.63 & 0.23 \\
$\mathrm{Cl}$ & $\mathrm{Q} 2$ & 8.5 & 2.73 & 518 & 1.26 & 1.10 & 0.39 \\
$\mathrm{C} 1$ & $\mathrm{Q} 3$ & 8.5 & 3.60 & 684 & 1.26 & 1.45 & 0.54 \\
$\mathrm{C} 1$ & $\mathrm{Q} 4$ & 8.5 & 5.46 & 1036 & 1.26 & 2.40 & 0.90 \\
$\mathrm{C} 2$ & $\mathrm{Q} 1$ & 13.0 & 1.14 & 320 & 1.86 & 0.20 & 0.07 \\
$\mathrm{C} 2$ & $\mathrm{Q} 2$ & 13.0 & 1.79 & 500 & 1.86 & 0.33 & 0.12 \\
$\mathrm{C} 2$ & $\mathrm{Q} 3$ & 13.0 & 2.36 & 660 & 1.86 & 0.48 & 0.17 \\
$\mathrm{C} 2$ & $\mathrm{Q} 4$ & 13.0 & 3.57 & 1000 & 1.86 & 0.80 & 0.30 \\
$\mathrm{C} 3$ & $\mathrm{Q} 1$ & 22.0 & 0.68 & 300 & 2.93 & 0.05 & 0.02 \\
$\mathrm{C} 3$ & $\mathrm{Q} 2$ & 22.0 & 1.06 & 466 & 2.93 & 0.08 & 0.03 \\
$\mathrm{C} 3$ & $\mathrm{Q} 3$ & 22.0 & 1.39 & 616 & 2.93 & 0.80 & 0.05 \\
$\mathrm{C} 3$ & $\mathrm{Q} 4$ & 22.0 & 2.11 & 932 & 2.93 & 0.21 & 0.08 \\
\hline & & & & & & &
\end{tabular}

detailed domain for configuration $\mathrm{C} 0$ that included the complete device from the inlet to the outlet water line was developed. As the aim of this more extensive domain was to calculate numerically the pressure drop, the honeycomb structure was included. The final unstructured mesh consisted of 56 million of cells formed mostly by hexahedrons. Isothermal tests were carried out for this problem for Q1, Q2 and Q3 with similar boundary conditions at the inlets, outlets and walls as the ones explained before. Fluid properties were calculated for a temperature of $20^{\circ} \mathrm{C}$. Results did not differ significantly from those obtained with the mesh used in the matrix of computational cases.

\section{Comparison between experimental and numerical isothermal results}

This comparison was carried out for all configurations and volume flow rates (a total of 12 cases) under isothermal conditions. However, in this section, and for the sake of brevity, only the most critical comparison case is presented. This case, that is the worst case scenario from the numerical computation point of view, is the one with the largest tip clearance C2 and highest volume flow rate Q4. Figs. 7-9 show the comparison between measured and computed profiles in the stagnation chamber (section $\mathrm{S}_{.1}$ and planes Pl1, Pl2 and Pl3), along the centerline of a channel (sections $S_{0}, S_{1}, S_{2}$ and $S_{3}$ for the plane Pl2), and on top of a fin (sections $S_{0}, S_{1}, S_{2}$ and $S_{3}$ for the plane Pl35). As it could be observed, there is a reasonably good agreement between computed and measured profiles that suggest that the computational tool thus formulated and developed can be used with confidence.

Also, the comparison has been performed at a global level in terms of the pressure drop. Discrepancies $(\varepsilon)$ between the experiment and the numerical values obtained when using the domain with the largest number of cells described in section 3 are summarized in Table 3 .

It could be observed in Figs. 7-9 that the larger discrepancies occur in section $\mathrm{S}_{-1}$ that is located in the stagnation chamber upstream of the entrance of the channels. This larger discrepancy could be caused by the local flow topology in that region. Specifically, in a very short distance, streamlines have to change direction abruptly twice: horizontal streamlines parallel to the bottom floor of the stagnation chamber became vertical when climbing the vertical wall leading to the entrance of the channels; and once they get there they have to become horizontal again to align themselves to the channels. On top of that, the 3D geometry imposed a spanwise velocity that further complicated the flow field and the structure of the streamlines. At the end of section 3, it was stated that a 56 million cells mesh was used for some comparison purposes. Then, it was checked that, in this case, the comparison between experimental and numerical results led to smaller discrepancies than those observed in Fig. 7 for section $\mathrm{S}_{-1}$ in the stagnation chamber. However, the improvement was marginal for the sections located in the channels region. Then, because of the very large computational cost associated to the 56 million cells mesh and, also, because of the fact that the region of interest for this study was the channel region, it was decided to proceed with the planned computational domains.

\section{Numerical results for the thermal cases and discussion}

First of all, as it was indicated previously in section 3, one additional configuration (C3) has been added to the previous ones. This new configuration, which was analyzed via CFD only, had a tip clearance of $20 \mathrm{~mm}$. This value is twice the tip clearance of configuration C2. Global values of the Nusselt number and pressure drop per unit length are given in Figs. 10 and 11 respectively. The Nusselt number, $\mathrm{Nu}$, is defined as:

$N u=\frac{Q_{w}}{\frac{k_{\infty}}{H}\left(T_{w}-T_{\infty}\right) A_{W}}$,

where $Q_{w}$ stands for the heat transfer rate (in W) across the heated bottom wall of the device, $\mathrm{H}$ is the height of the channels $(10 \mathrm{~mm})$ and $\mathrm{A}_{\mathrm{w}}$ represents the total surface of the heated wall for each configuration, that is, $0.03 \mathrm{~m}^{2}$ for $\mathrm{C} 0$ and $0.0425 \mathrm{~m}^{2}$ for $\mathrm{C} 1, \mathrm{C} 2$ and $\mathrm{C} 3$. 


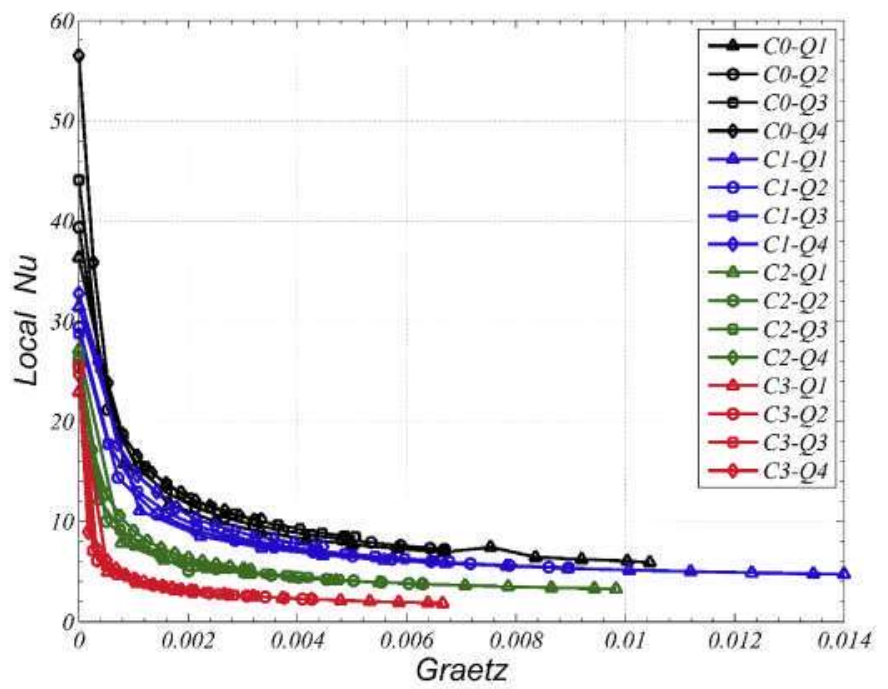

Fig. 12. Local Nusselt number as function of Graetz number.

As expected, $\mathrm{Nu}$ grows along with the volume flow rate and decreases when the tip clearance increases. At the same time, the pressure drop also grows along with the volume flow rate and decreases when the tip clearance increases. However, from configuration $\mathrm{C} 0$ to $\mathrm{C} 3 \mathrm{Nu}$ decreases, typically, by factor of about 3 , while the pressure drop decreases by a factor of about 30 (ten times as much).

The first question, now, is to understand whether the simultaneous decrease in both $\mathrm{Nu}$ and pressure drop is caused, only, by the fact that the flow is neither hydrodynamically nor thermally developed, or tip clearances play some specific role. To asses this question, some data are presented, first, in Table 4. This includes, for each configuration and flow rate: cross section area, mean velocity, hydraulic diameter and Reynolds number based on the hydraulic diameter with properties evaluated at the inlet temperature of $35^{\circ} \mathrm{C}$. Furthermore, two columns are added containing the actual computed pressure drop and the estimated pressure drop in isothermal conditions following the method described by Shah and London [27] and summarized later by White [29].

The method described in Refs. [29] and [27] provides an estimate for the pressure drop in an isothermal channel in which the flow is developing but has not reached hydrodynamically developed conditions. Details of the method can be found in section 4.9 in Ref. [29]. The cross section geometries addressed in Ref. [27] are, among many others, rectangular. Unfortunately, no information is provided on a cross section shape as the one that is being addressed in this article. Then, to carry out the comparison, an equivalent cross section rectangular geometry was generated for each case presented in Table 4. For example, for the case C3-Q4 the cross section area is $22 \mathrm{~cm}^{2}$ and the hydraulic diameter is $2.93 \mathrm{~cm}$. Then, the equivalent rectangle that has the same area and hydraulic diameter is the one whose dimensions are $13.35 \mathrm{~cm} \times 1.65 \mathrm{~cm}$. In this case, the computed pressure drop with the actual geometry is $0.21 \mathrm{~Pa}$, while the one estimated, using the equivalent geometry, with the method of White [29] and Shah and London [27] is $0.08 \mathrm{~Pa}$. That is, the computed pressure drop doubles the estimated (approximate) value. Furthermore, the comparison presented in
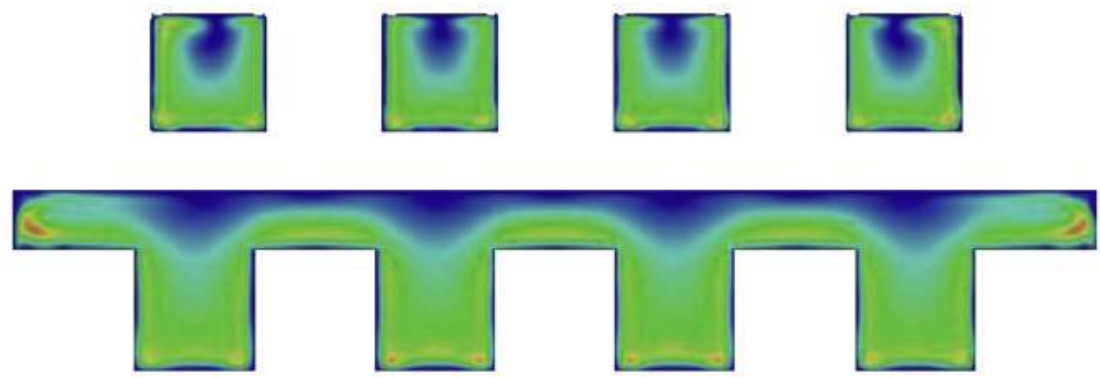

C1-Q4-S0

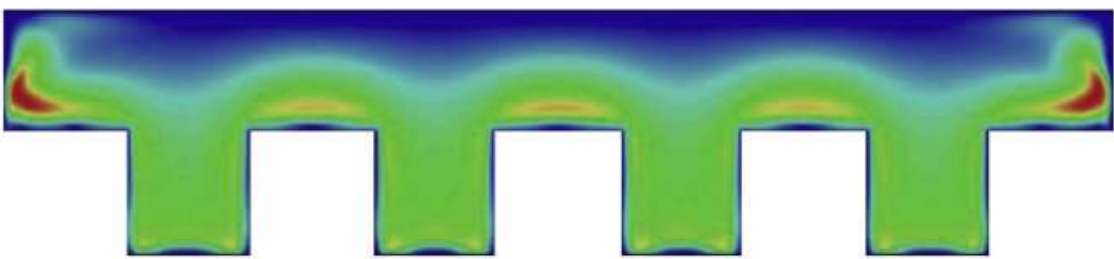

C2-Q4-S0
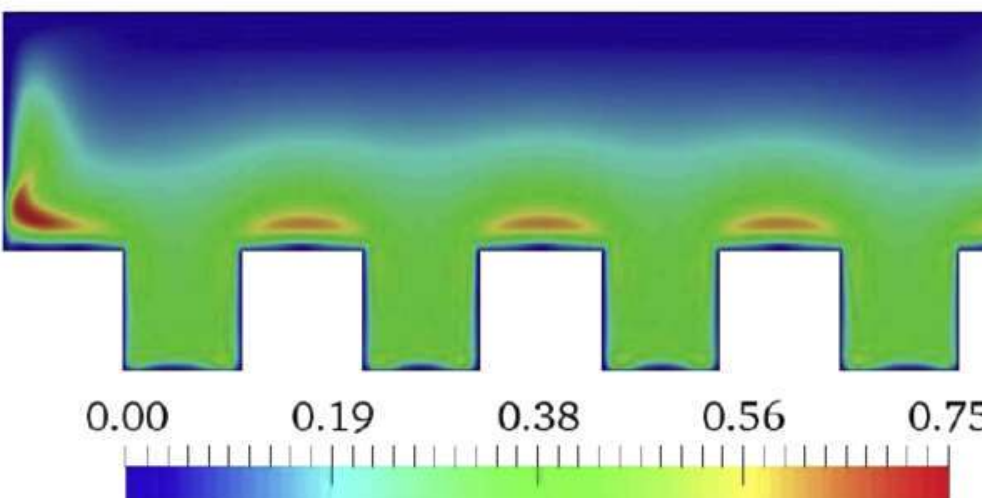

C3-Q4-S0

Fig. 13. Dimensionless transverse velocity plots for configurations $\mathrm{C} 0$ to $\mathrm{C} 3$ and flow rate $\mathrm{Q} 4$ at section $\mathrm{S} 0$. 

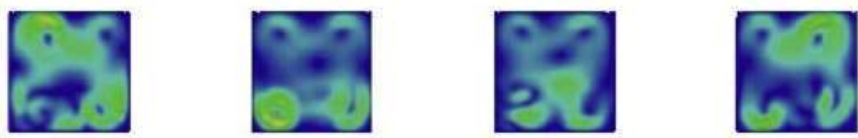

C0-Q4-S1

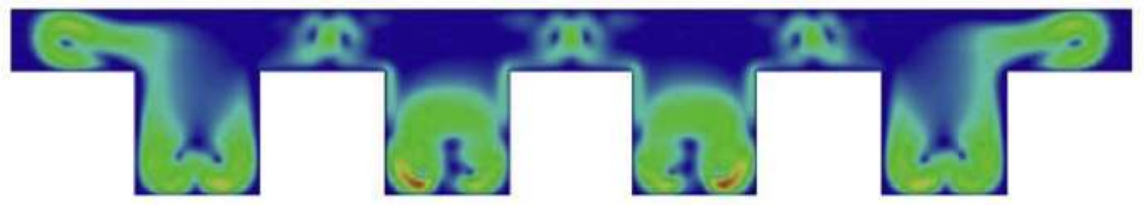

C1-Q4-S1

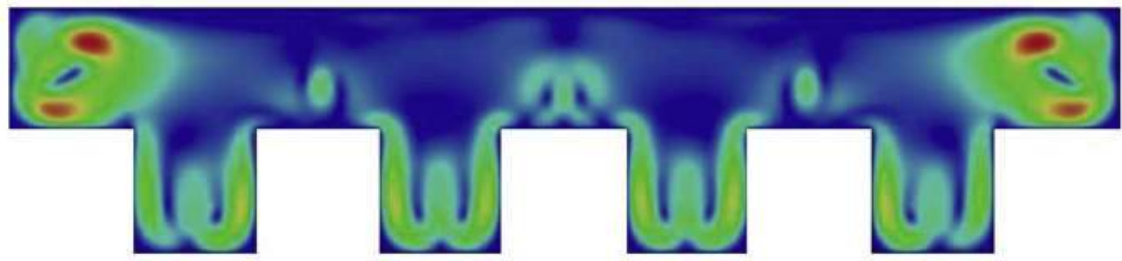

C2-Q4-S1

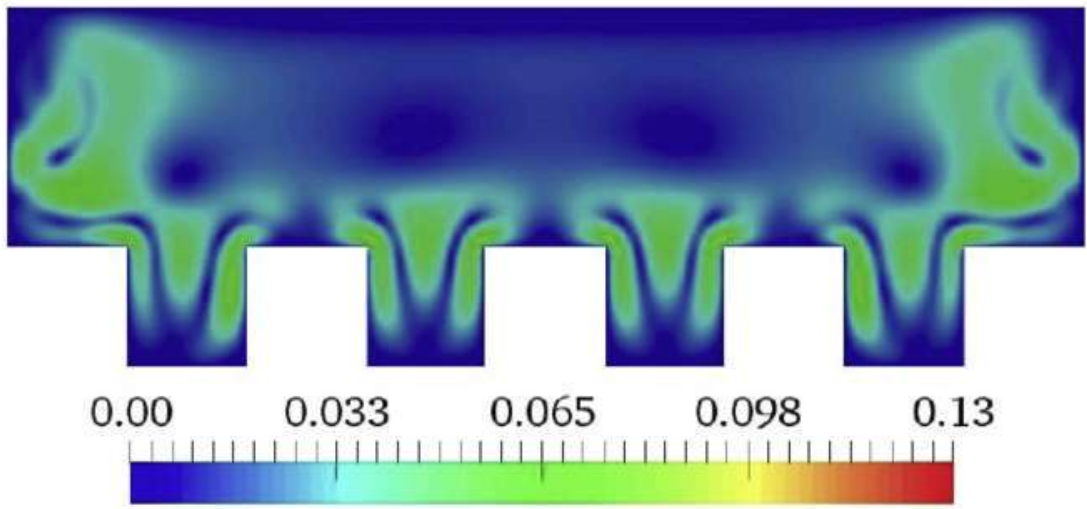

C3-Q4-S1

Fig. 14. Counterpart of Fig. 13 at section S1.

Table 4 considers isothermal conditions for the pressure drop estimate $([19,20])$ and thermal conditions for the pressure drop CFD computation. This means that in the case of an isothermal CFD computation with larger viscosity and smaller Re, the pressure drop should be even higher (in laminar flows the pressure drop scales with the inverse of $\mathrm{Re})$; thereby enlarging the difference between computed and estimated results. To further justify this statement, this particular C3-Q4 case has been computed in isothermal conditions and it was found that the actual pressure drop was $0.27 \mathrm{~Pa}$. Then, this seems to suggest that the tip clearance modifies the flow topology in a way that causes the pressure drop to be significantly higher than it should be. It could be counter argued that this is so because of the presence of the four channels in the test geometry. However, it is to be noted that in this $\mathrm{C} 3$ configuration the total cross section area was $22 \mathrm{~cm}^{2}$ while the cross section area of the channels was $4 \mathrm{~cm}^{2}$ only.

The second way to evaluate the global results is connected to the heat transfer rates. To do it, the local Nusselt number $\left(\mathrm{hD}_{\mathrm{H}} / \mathrm{k}\right)$ along the $x$ coordinate (see Fig. 1) has been plotted as function of the Graetz number $\left(\mathrm{x} / \mathrm{D}_{\mathrm{H}} \mathrm{Re}_{\mathrm{DH}} \mathrm{Pr}\right)$. The properties needed to obtain $\mathrm{k}, \mathrm{Re}_{\mathrm{DH}}$ and $\mathrm{Pr}$ were evaluated at the film temperature. This film temperature was the average between the bulk temperature (the average cross section temperature at coordinate $\mathrm{x}$ ) and the wall temperature. The results obtained for all configurations and flow rates are presented in Fig. 12.

The main aspect to be noted in the results resented in Fig. 12 is that the local $\mathrm{Nu}$ vs Graetz curves tend to collapse into four different families that correspond, precisely, to the four configurations being considered. Then, it could be stated that the geometry is one of the leading governing parameters of the problem since no single $\mathrm{Nu}$ vs
Graetz curve has been found that collapses all 16 cases that have been computed. That is, the previous results seem to suggest that the specific details of the geometry exert some influence upon the hydrodynamics and thermal behavior of the problem and that the state of either hydrodynamics or thermal development is not the only explanation for what has been observed.

To illustrate the details of the flow field, Fig. 13 shows, first, the dimensionless modulus of the transverse velocity defined as:

$\left|\widetilde{U_{y z}}\right|=\frac{\left[\left(U_{y}\right)^{2}+\left(U_{z}\right)^{2}\right]^{1 / 2}}{U_{\infty}}$

for the four configurations $\mathrm{C} 0$ to $\mathrm{C} 4$ at the same flow rate $\mathrm{Q} 4$ in section $\mathrm{S}_{0}$ (the inlet section of the channels, see Fig. 13, In each subplot of Fig. 13, the value of $U_{\infty}$ used to render the transverse velocity dimensionless is the mean velocity corresponding to each selected configuration and flow rate (the flow rate divided by the cross-section area). The following aspects could be noted in the results presented in Fig. 13:

- The larger the tip clearance is, the larger the typical transverse velocities at section $\mathrm{S}_{0}$ (referred to their own mean velocity) are. This occurs not only at the far left and far right sides of the cross section geometry but, also, on top of the fins.

- The above mentioned presence of larger transverse velocities means that flow accommodation induces a 3D flow topology that has the practical effect of transporting heat from the heated walls into the main bulk flow. Or to put it in another words: this 3D flow topology departs from the classical quasi-one dimensional flow structure of 

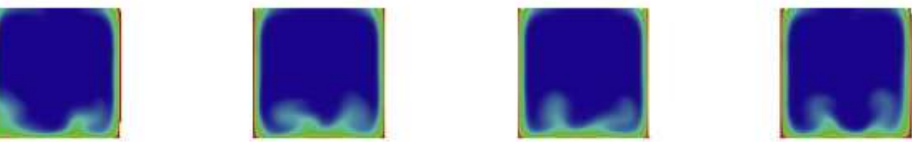

C0-Q4-S1

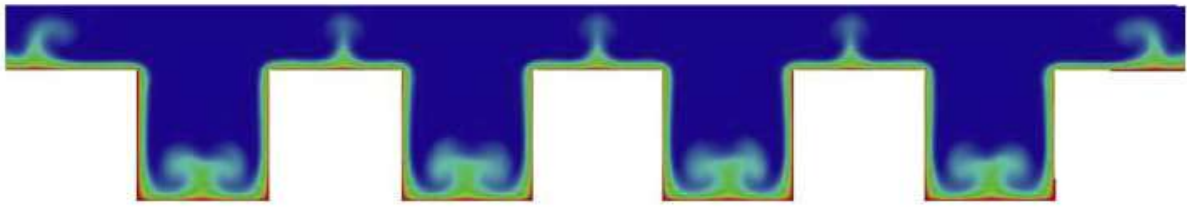

C1-Q4-S1

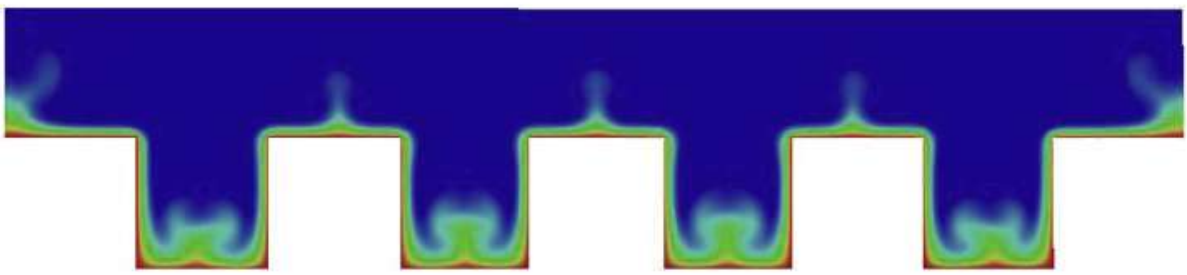

C2-Q4-S1
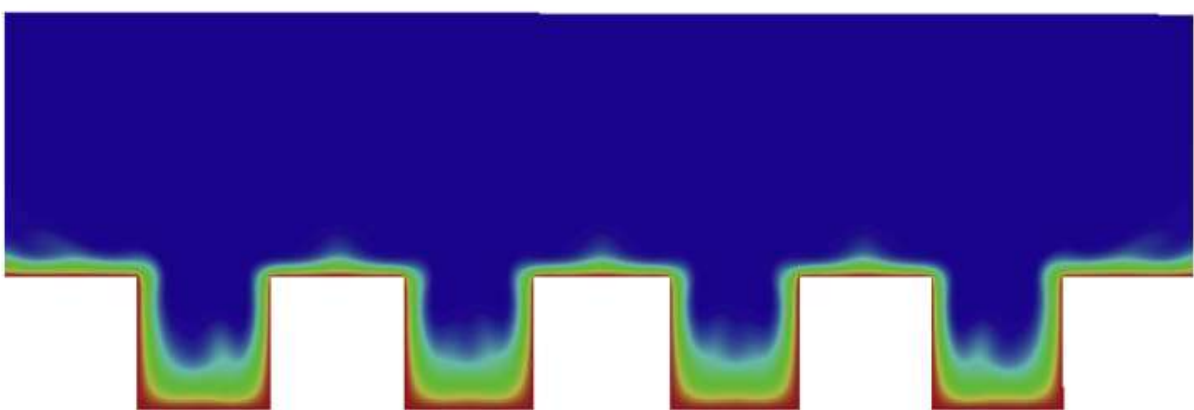

\section{C3-Q4-S1}

35.0

43.8

52.5

61.2

70.0

$T(\stackrel{\circ}{C})$

Fig. 15. Temperature plots for configurations $\mathrm{C} 0$ to $\mathrm{C} 3$ and flow rate $\mathrm{Q} 4$ at section $\mathrm{S} 1$.

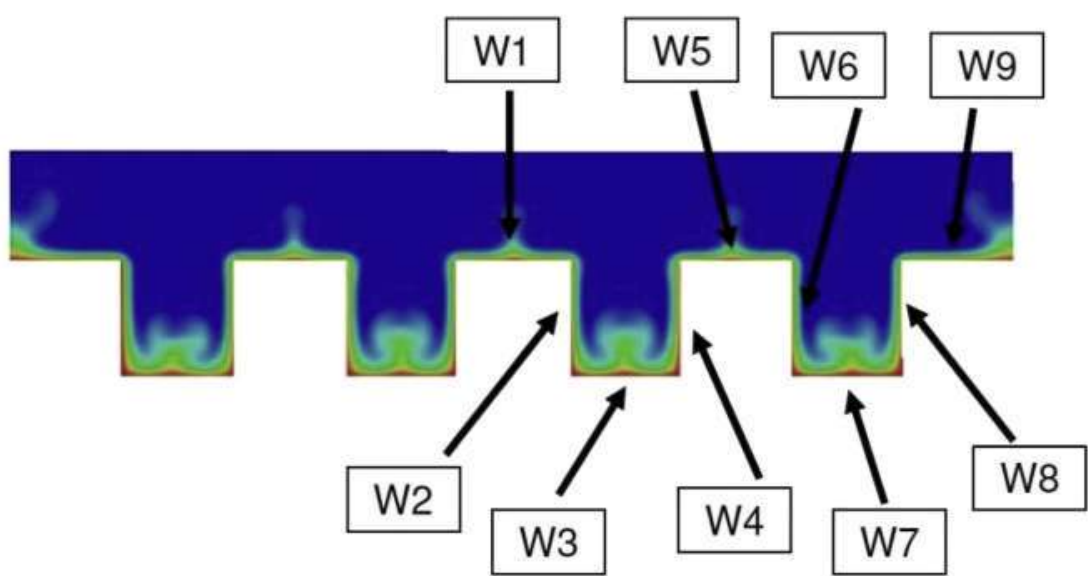

Fig. 16. Sketch showing the key used to name walls in Fig. 17-20 below.

conventional channels.

- Stream-wise velocities (z direction) in configuration C0 are larger than, for example, in configuration $\mathrm{C} 3$ and this translates into higher heat transfer rates (higher $\mathrm{Nu}$ ). This is obvious, but the important point is that the 3D structures (made apparent by the modulus of the transverse velocities) that appear in the configurations with tip clearances have the practical effect of alleviating Nu degradation.

- The larger the tip clearance, the larger the flow region (close to top wall) that is not affected by the local details of the flow around the fin tips. Transverse velocities in this region are very small and heat transport is expected to be small too. Then, there is a balance between of $\mathrm{Nu}$ alleviation in the area close to the fins and flow that 


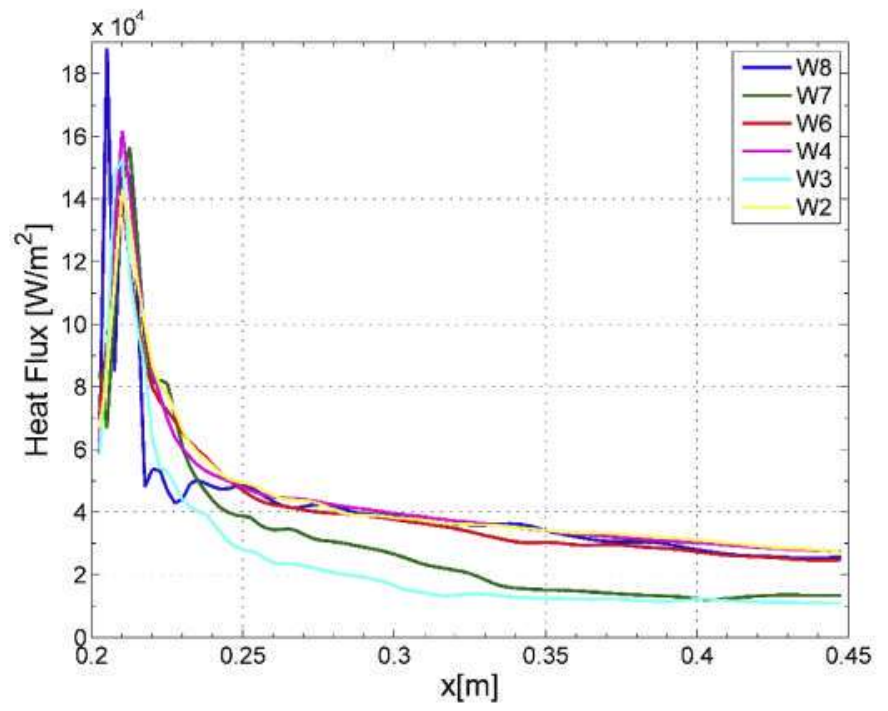

Fig. 17. Local heat flux at the walls as a function of $x$ for the case CO-Q4.

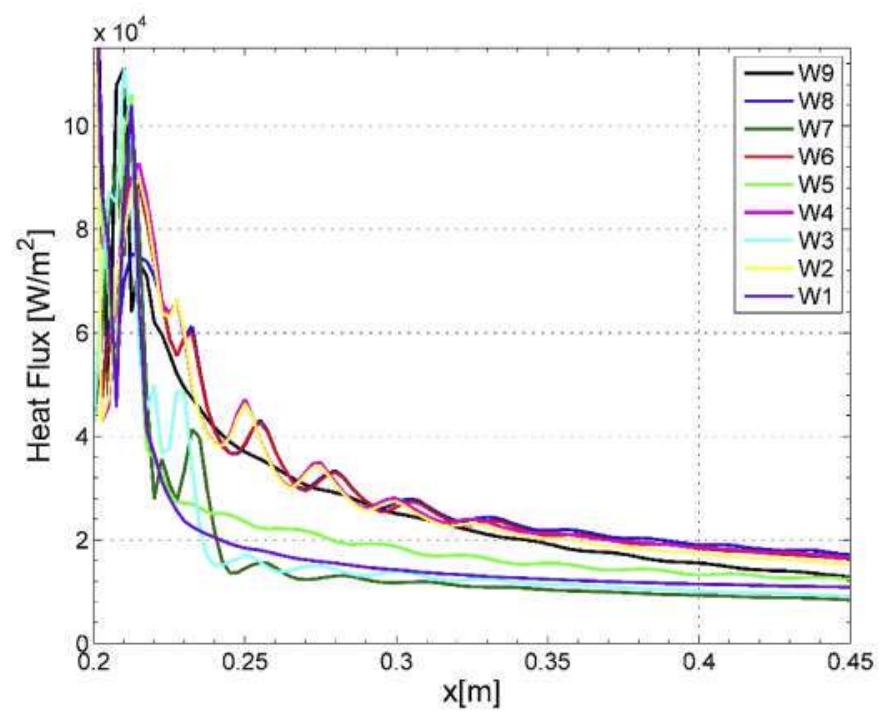

Fig. 18. Local heat flux at the walls as a function of $x$ for the case C1-Q4.

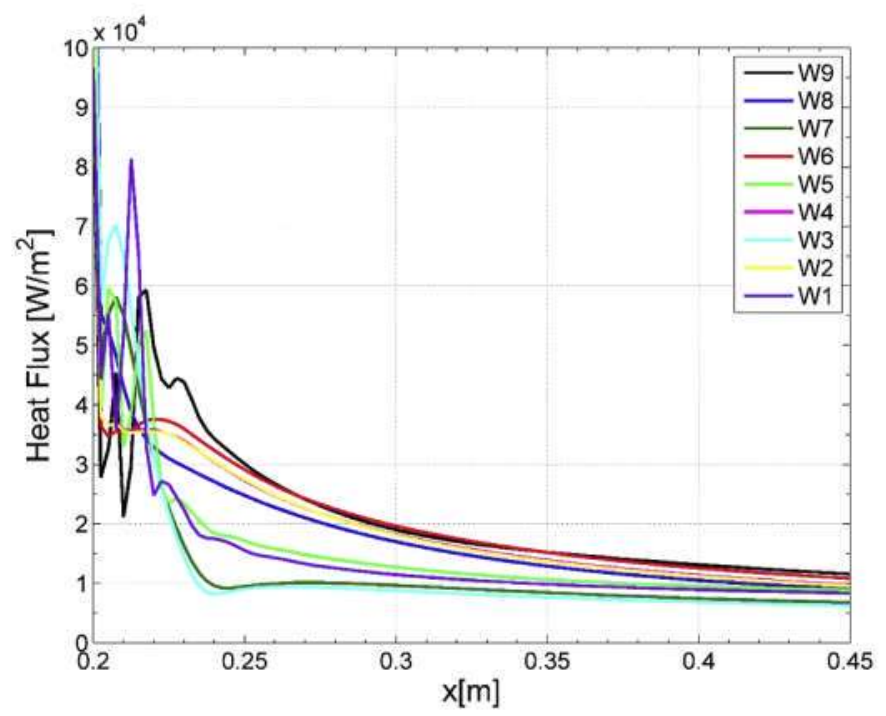

Fig. 19. Local heat flux at the walls as a function of $x$ for the case C2-Q4. goes nearly undisturbed close to the top wall. That is: there should be an optimum tip clearance for each flow rate that minimizes $\mathrm{Nu}$ losses and minimizes pressure drop as well (that are related to the tip clearance itself).

The next question is to ascertain for how long along the $\mathrm{x}$ streamwise coordinate the distinct behavior shown in Fig. 13 is present. The answer is provided in Fig. 14 where the counterpart of Fig. 13 is shown at section $\mathrm{S}_{1}$. There, it could be observed that the transverse velocity structures get weaker very soon and that typical transverse velocities at this section $S_{1}$ are of the order of 6 times smaller than at section $S_{0}$.

The cross-section temperature plots associated to the transverse velocity profiles of Fig. 14 are presented in Fig. 15. It is of interest to note the plumes of hot fluid that can be noticed at the bottom of the channels and on top of the fins (especially for configurations C1 and C2). Again, these plumes that transport heat from the walls into the main bulk of fluid could be explained because of the transverse velocity structures that were discussed before. Plumes can be observed, also, in configuration $\mathrm{CO}$ but they are smaller than in $\mathrm{C} 1$ and $\mathrm{C} 2$. The area of heated flow at the bottom of the channels is largest in configuration $\mathrm{C} 3$ but the biggest portion of undisturbed cold flow is responsible for the overall smaller $\mathrm{Nu}$.

The results presented in Fig. 15 suggest that it is of interest to plot the evolution of the heat flux $\left(\mathrm{W} / \mathrm{m}^{2}\right)$ at the bottom lines, side lines, and top lines of the fins as a function of the $\mathrm{x}$ coordinate along the channels. This is done for cases, C0-Q4, C1-Q4, C2-Q4, and C3-Q4 in Figs. 17-20. Fig. 16 presents a sketch to show the key that has been used to name walls in Figs. 17-20.

The following aspects could be noted in these figures:

- Three different heat transfer regions could be discerned along the length of the channels for the four configurations: region A (from $\mathrm{x}=0.20 \mathrm{~m}$, the channel's entrance, up to approximately $x=0.23 \mathrm{~m})$, region $\mathrm{B}(\mathrm{x}=0.23 \mathrm{~m}$ up to $\mathrm{x}=0.35 \mathrm{~m})$, and region $\mathrm{C}$ ( $x=0.35 \mathrm{~m}$ up to $\mathrm{x}=0.45 \mathrm{~m}$, the channel's exit).

- The largest heat fluxes can be found in region A, and this applies to all heated walls W1 to W9. Unfortunately, this region A is quite narrow ( $3 \mathrm{~mm}$ in the present case) which prevents from obtaining larger values of the global Nu. The smaller the gap is, the higher the heat fluxes are in this region, being a consequence of the larger average velocities.

- The Nu curves present a distinct behavior in region B that is about $12 \mathrm{~mm}$ long (half the device length). For all configurations, the higher values of $\mathrm{Nu}$ are obtained for walls W9, W8, W6, W4, and W2. These are the side walls of the fins and the top wall of the fin located furthest away from the device symmetry axis. The lower values of $\mathrm{Nu}$ are obtained for walls $\mathrm{W} 7$ and $\mathrm{W} 3$. These are the bottom walls of the channels. However, distinct behaviors are obtained for the top walls of the fins W5 and W1. While for configuration $\mathrm{C} 3 \mathrm{Nu}$ values at these walls are high and equivalent to those of the side walls, for configurations $\mathrm{C} 1$ and $\mathrm{C} 2$, intermediate values of $\mathrm{Nu}$ are obtained. All this suggests that the sides of the fins are the most favorable places from the heat transfer point of view in these types of configurations with a small gap present.

- In region $\mathrm{C}$, the other half of the device, Nusselt numbers tend to homogenize for all walls. There are still differences but they are much smaller than in region $B$.

- From the point of view of a practical thermal engineering design, region $B$ is interesting because: a) it is large (it occupies half the device), b) its $\mathrm{Nu}$, on the average, nearly doubles its limiting value on the second half of the device, and c) specific locations where $\mathrm{Nu}$ is distinctly higher (the fin's side walls) can be clearly identified so that, if needed, heat sources can be placed close to these high heat transfer regions. In this context, it is to be noted that the bottom channel walls quickly reach their limiting heat transfer behavior, while the fin's side walls retain at higher $\mathrm{Nu}$ (three times as large) 


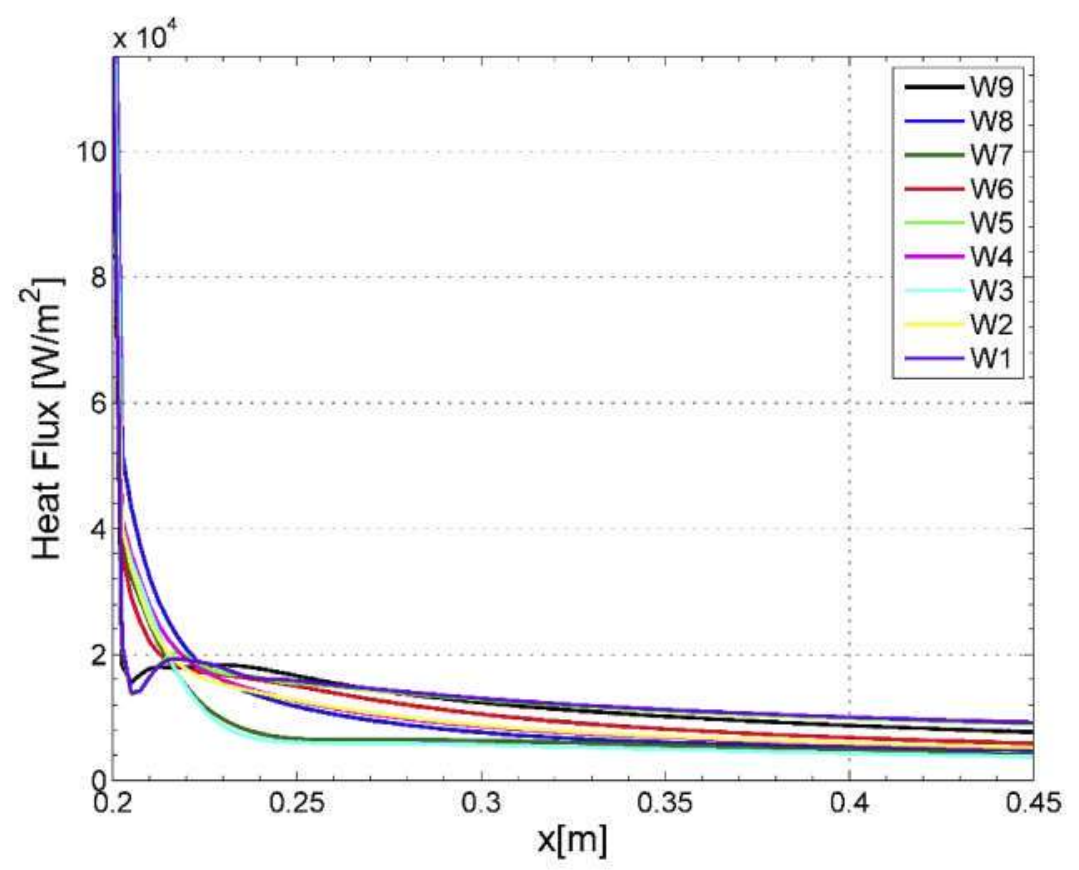

Fig. 20. Local heat flux at the walls as a function of $x$ for the case C3-Q4.

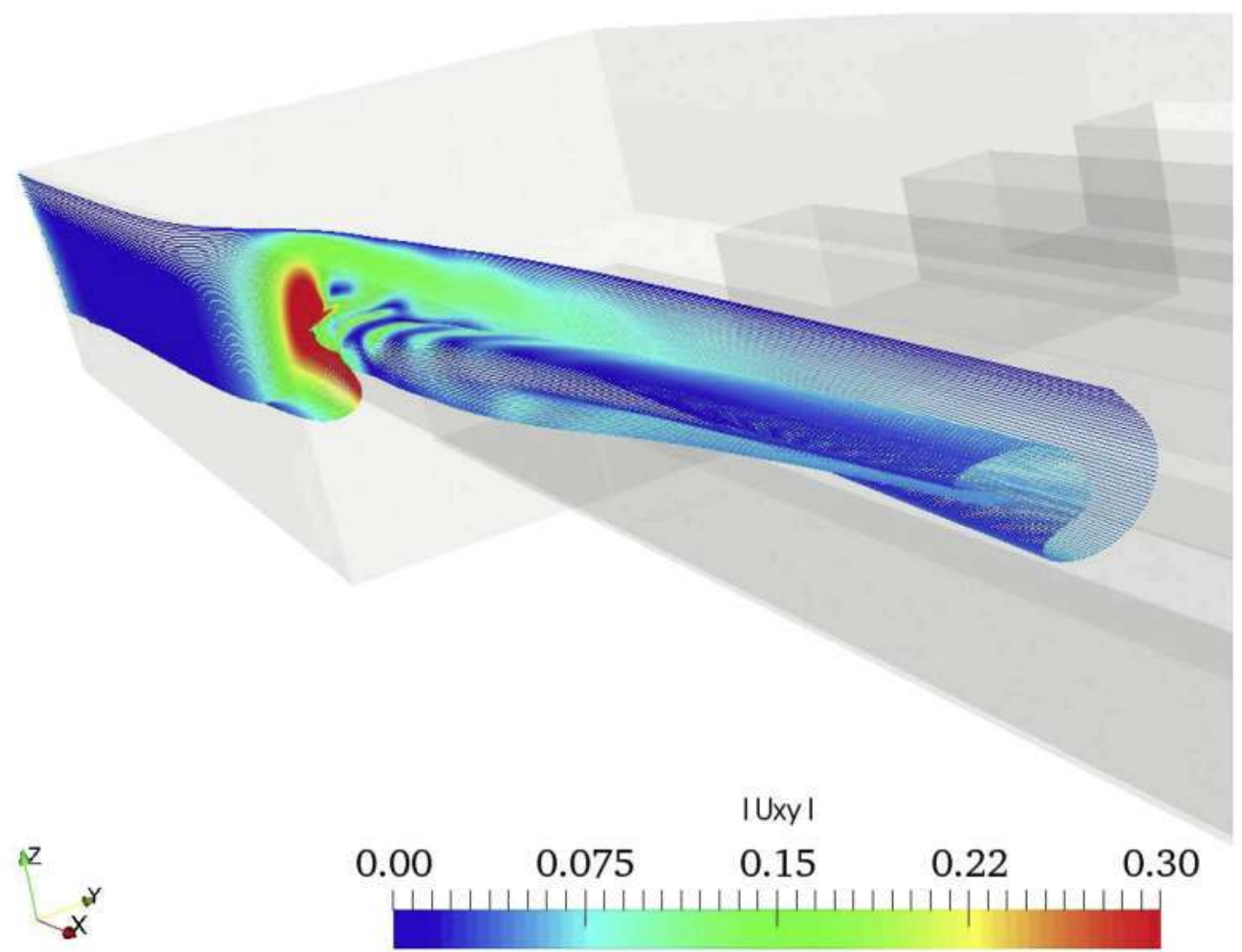

Fig. 21. Flow streamlines (for the C2-Q4 thermal simulation) colored by the transverse velocity defined in relation (10).

for nearly half of the device length.

Finally, visualization of the flow topology can be improved by means of plotting 3D streamlines. This, again in done for case C2-Q4 and the results are presented in Fig. 21. The view is from the device outlet looking towards the inlet (the viewer sees the incoming flow). The streamlines have been colored according to the value of $\left|\widetilde{U}_{y z}\right|$ defined in relation (10).

It could be observed that the streamlines fold over the top of the fins, and that transverse velocities in the regions close to the fin's side walls are large, thereby lending support to the observed higher $\mathrm{Nu}$ in these regions. The folding of the streamlines is also interesting because it contributes to increase transport in the bulk region of the flow.

\section{Conclusions}

- Even though the geometry that has been addressed is complex, the flow solver that has been generated for analysis purposes is 
reasonably accurate. Its accuracy has been assessed by comparing its results with a series of PIV visualizations obtained from dedicated experimental tests.

- It appears that the behavior of both heat transfer and pressure drop on this device cannot be explained in view, only, of flow development and thermal development aspects. This is so because the Nusselt versus Graetz curves that have been generated do not collapse into a single fit; instead, they collapse into several families that are governed by the tip clearance parameter. This suggest that the specific geometries of typical tip clearance based configurations play a distinct role on the flow topology and, accordingly, on heat transfer and pressure drop.

- It has been found that, when looking at the local $\mathrm{Nu}$, three distinct regions are present in the device. These are: a narrow high $\mathrm{Nu}$ region located at the entrance of the channels, a homogenized $\mathrm{Nu}$ region located at the far end of the device, and an intermediate region of moderately high $\mathrm{Nu}$ that occupies half of the device length and in which $\mathrm{Nu}$ changes significantly depending of the location: bottom of the channels, sides of the fins, or top of the fins. From a thermal engineering point of view, this region is interesting because it is large and because it shows a variety of heat transfer behaviors. Therefore, it is a region amenable for optimization (outside of the scope of the present article).

- Visualization of 3D streamlines shows that transverse velocities are high close to side of the fins, thereby lending support to the observed high $\mathrm{Nu}$ in these regions. Furthermore, downstream folding of these streamlines (not observed in a conventional quasi-one dimensional straight channel based heat sink) suggests that mixing could be enhanced by promoting this folding of the flow topology.

\section{Acknowledgements}

F. Sastre and A. Velazquez were funded by the Spanish Ministry of Economy and Competitiveness (Ministerio de Economia y Competitividad) under research contract DPI2016-75296-P. They gratefully acknowledge this support.

\section{Appendix A. Supplementary data}

Supplementary data related to this article can be found at http://dx. doi.org/10.1016/j.ijthermalsci.2018.05.036.

\section{References}

[1] E.M. Sparrow, B.R. Baliga, S.V. Patankar, Forced convection heat transfer from a shrouded fin array with and without tip clearance. J Heat Tran 100 (1978) $572-579$.

[2] F.M. Sparrow, D.S. Kaddle, Effect of tip to shroud clearance on turbulent heat transfer from a shrouded, longitudinal fin array, J Heat Tran 108 (1986) 519-524.

[3] R.A. Wirtz, W. Chen, R. Zhou, Effect of flow bypass on the performance of long. itudinal fin heat sinks. J Electron Packag 116 (1994) 206-211.

[4] C. Cretzer, J. Visser, Compact modelling of forced flow in longitudinal fin, J Electron Packag 125 (2003) 319-324.

[5] J.Y. Min. S.P. Jang, S.J. Kim, Effect of tip clearance on the cooling performance of a micro-channel heat sink, Int J Heat Mass Tran 47 (2004) 1099-1103.

[6] M. Dogruoz, M. Urdaneta, A. Ortega, Experiments and modeling of the hydraulic resistance and heat transfer of in-line square pin heat sinks with top by-pass flow, Int J Heat Mass Tran 48 (2005) 5058-5071.

[7] T.M. Jeng, A porous model for the square pin-fin heat sink situated in a rectangular channel with laminar side-bypass flow, Int J Heat Mass Tran 51 (2008) 2214-2226.

[8] A. Rozati, D.K. Tafti, N.E. Blackwell, Effect of pin tip clearance on flow and heat transfer at low Reynolds numbers, J Heat Tran 130 (071704) (2008) 1-10.

[9] K.A. Moores, J. Kim, Y.K. Joshi, Heat transfer and fluid flow in shrouded pin fin arrays with and without tip clearance, Int J Heat Mass Tran 52 (2009) 5978-5989.

[10] M. Reyes, J.R. Arias, A. Velazquez, J.M. Vega, Experimental study of heat transfer and pressure drop in micro-channel based heat sinks with tip clearance, Appl Therm Eng 31 (2011) 887-893.

[11] J.F. Tullius, T.K. Tullius, Y. Bayazitoglu, Optimization of short micro pin fins in minichannels, Int J Heat Mass Tran 55 (2012) 3921-3932.

[12] Z. Liu, N. Guan, C. Zhang, Influence of tip clearance on heat transfer efficiency in micro-cylinders-group heat sink, Exp Therm Fluid Sci 46 (2013) 64-73.

[13] C. Liang, J.R. Arias, A. Velazquez, Tip clearance effects on microchannel-based heat sink with polymeric fluid, J Thermophys Heat Tran 30 (2) (2016).

[14] D. Mei, X. Lou, M. Qian, Z. Yao, L. Liang, Z. Chen, Effect of tip clearance on the heat transfer and pressure drop performance in the micro-reactor with micro-pin-fin arrays at low Reynolds number, Int J Heat Mass Tran 70 (2014) 709-718.

[15] J.Y. Ho, K.K. Wong, K.C. Leong, T.N. Wong, Convective heat transfer performance of airfoil heat sinks fabricated by selective laser melting, Int J Therm Sci 114 (2017) 213-228.

[16] X. Li, J. Zhang, X. Tan, Effects of piezoelectric fan on overall performance of airbased micro pin-fin heat sink, Int J Therm Sci 126 (2018) 1-12.

[17] R. Jadhav, C. Balaji, Fluid flow and heat transfer characteristics of a vertical channel with detached pin-fin arrays arranged in staggered manner on two opposite endwalls, Int J Therm Sci 105 (2016) 57-74.

[18] A. Giri, B. Das, A numerical study of entry region laminar mixed convection over shrouded vertical fin arrays, Int J Therm Sci 60 (2012) 212-224.

[19] "www.openfoam.com,".

[20] E. Martin, A. Velazquez, Effect of span length and temperature on the 3D confined flow around a vortex promoter. Int I Heat Fluid Flow 32 (2011) 1173-1185.

[21] J. Ferziger, P. Milovan, Computational Methods for Fluid Dynamics, second ed., Springer, 1999.

[22] OpenFOAM User Guide. Version 2.3.1, third ed., OpenFOAM Foundation, Dec 2014 Copyright 2011-2014.

[23] L. Caretto, A. Gosman, S. Patankar, D. Spalding, Two calculation procedures for steady three-dimensional flows with recirculation, International Conference of Numerical Methods in Fluid Dynamics, Paris, 1972.

[24] H. Jasak, Error Analysis and Estimation for the Finite Volume Method with Applications to Fluid Flows, PhD thesis Imperial College London, 1996.

[25] Y. Saad, Iterative Methods for Sparce Linear Systems, second ed., Society for Industrial and Applied Mathematics, 2003.

[26] F. Moukalled, L. Mangani, M. Darwish, The Finite Volume Method in Computational Fluid Dynamics: an Advanced Introduction with OpenFOAM ${ }^{s}$ and Matlab, Springer. 2016.

[27] R.K. Shah, A.L. London, Laminar Flow Forced Convetion in Ducts, Academic Press New York, 1978.

[28] R.W. Lyczkowski, C.W. Solbrig, D. Gidaspow, Forced Convective Heat Transfer in Rectangular Ducts - General Case of wall Resistances and Pheripheral Conduction, Institute of Gas Technology, Tech. Info. Center, File 3229, Chicago, 1969.

[29] F.M. White, Viscous Fluid Flow, McGraw-Hill, New York, 1991. 